\title{
Representing time-dependent freezing behaviour in immersion mode ice nucleation
}

\author{
R. J. Herbert ${ }^{1}$, B. J. Murray ${ }^{1}$, T. F. Whale ${ }^{1}$, S. J. Dobbie ${ }^{1}$, and J. D. Atkinson ${ }^{1 \text {,* }}$ \\ ${ }^{1}$ School of Earth and Environment, University of Leeds, Leeds, LS2 9JT, UK \\ * now at: Institute for Atmospheric and Climate Science, Universitaetstr. 16, ETH Zurich, Switzerland \\ Correspondence to: R. J. Herbert (r.herbert@see.leeds.ac.uk) and B. J. Murray (b.j.murray@leeds.ac.uk)
}

Received: 29 November 2013 - Published in Atmos. Chem. Phys. Discuss.: 17 January 2014

Revised: 17 June 2014 - Accepted: 9 July 2014 - Published: 22 August 2014

\begin{abstract}
In order to understand the impact of ice formation in clouds, a quantitative understanding of ice nucleation is required, along with an accurate and efficient representation for use in cloud resolving models. Ice nucleation by atmospherically relevant particle types is complicated by interparticle variability in nucleating ability, as well as a stochastic, timedependent, nature inherent to nucleation. Here we present a new and computationally efficient Framework for Reconciling Observable Stochastic Time-dependence (FROST) in immersion mode ice nucleation. This framework is underpinned by the finding that the temperature dependence of the nucleation-rate coefficient controls the residence-time and cooling-rate dependence of freezing. It is shown that this framework can be used to reconcile experimental data obtained on different timescales with different experimental systems, and it also provides a simple way of representing the complexities of ice nucleation in cloud resolving models. The routine testing and reporting of time-dependent behaviour in future experimental studies is recommended, along with the practice of presenting normalised data sets following the methods outlined here.
\end{abstract}

\section{Introduction}

Clouds are known to exert a significant radiative impact on Earth's energy budget with lower altitude clouds making the largest net contribution due to their dominating albedo effect and global spatial extent (Hartmann et al., 1992). Observational studies have shown that these clouds are commonly supercooled and can exist in a mixed-phase state (Zhang et al., 2010). Sassen and Khvorostyanov (2007) showed that the ra- diative properties of these mixed-phase clouds are dominated by the supercooled liquid phase, with increasing ice content decreasing their cooling effect. Therefore, along with cloud lifetime effects an enhanced ice formation process could lead to a significant climatic radiative impact. The formation and sublimation of ice particles also has direct impacts on cloud dynamics through latent heat processes (Dobbie and Jonas, 2001), and the cold rain process, estimated to account for $50 \%$ of all precipitation in midlatitude regions and $30 \%$ in tropical regions (Lau and $\mathrm{Wu}, 2003$ ), is sensitive to the cloud ice-water content. Therefore a thorough understanding of how ice is formed, along with an appropriate representation in models, is clearly important for correctly quantifying the impact of clouds on climate and weather.

In the atmosphere relatively pure liquid droplets will tend to supercool down to around $237 \mathrm{~K}$ before freezing homogeneously. The inclusion of an ice nucleating particle (INP) can act as a catalyst and allow freezing to occur at higher temperatures. This process is generally split into four primary pathways determined by the interaction between the INP and the parent phase (Vali, 1985): immersion freezing occurs when the INP is immersed within a supercooled liquid droplet; contact freezing through an outside-in or inside-out contact between an INP and the air-liquid interface of a supercooled droplet; deposition mode occurs under ice-supersaturated conditions via deposition of water vapour onto the INP surface without the formation of bulk liquid water; and condensation mode involves the condensation of water vapour onto the INP prior to freezing. Observational studies show strong evidence that above homogeneous freezing temperatures the formation of ice is commonly preceded by the activation of the liquid phase, hence the glaciation of an air parcel 
transitions through a mixed-phase regime (Ansmann et al., 2009; de Boer et al., 2011; Field et al., 2012; Westbrook and Illingworth, 2013). Ansmann et al. (2009) found that in $99 \%$ of cases the production of ice occurred after the formation of a liquid phase and, similarly, de Boer et al. (2011) found that air parcels under ice-supersaturated conditions did not produce ice until after a liquid layer was formed. This suggests that deposition and condensation mode ice nucleation play a secondary role in the glaciation of these clouds. Contact nucleation is not thought to be significant in deep convection (Cui et al., 2006; Phillips et al., 2007), but may be important in some situations, particularly where droplets are evaporating (Ansmann et al., 2005; Durant and Shaw, 2005; Moreno et al., 2013). This study focuses on the immersion freezing mode due to its potential primary atmospheric importance.

Heterogeneous ice nucleation is fundamentally a stochastic process, meaning that the probability of nucleation at a specific temperature depends on both the INP surface area and the time available for nucleation. In addition to the variability in freezing temperature associated with the stochastic nature of nucleation, there is often a strong interparticle variability with some particles capable of nucleating ice at much higher temperatures than others. The ability for an INP to catalyse ice nucleation is dependent on its physiochemical properties; these may be crystallographic, chemical, or surface features such as cracks or defects that provide sites where the energy barrier to nucleation is at a local minimum (Pruppacher and Klett, 1997).

Experimental studies have shown that atmospherically relevant INPs exhibit an extremely diverse range in their ability to nucleate ice heterogeneously (Murray et al., 2012; Hoose and Mohler, 2012). For example, bacteria species belonging to the Pseudomonas genera catalyse freezing at temperatures above $265 \mathrm{~K}$ and exhibit a steep function of freezing rate (Wolber et al., 1986; Mortazavi et al., 2008), whereas mineral dust has been found to catalyse freezing at lower temperatures and exhibit a weaker gradient (Niedermeier et al., 2011). Along with this variability in nucleating ability, the importance of the stochastic, time-dependent nature of ice nucleation is also reported to vary between INP species. Repeated freeze-thaw cycles of single droplets performed by Vali (2008) with two soil samples resulted in < $1 \mathrm{~K}$ variation in freezing temperatures, which was much smaller than the variability in freezing temperature over an array of droplets. On this basis Vali (2008) argued that the time dependence of nucleation is of secondary importance. Similarly, Ervens and Feingold (2013) recently performed a sensitivity study which highlighted changes in temperature as being the most important factor in droplet freezing sensitivity. Nevertheless, a number of studies show that there is a sensitivity of ice nucleation to time. For example, Kulkarni and Dobbie (2010) used a deposition mode stage and reported that the fraction of dust particles activated to ice increased with time under constant temperature and relative humidity conditions. Using an immersion mode cold-stage instrument with cooling rates from 1 to $10 \mathrm{~K} \mathrm{~min}^{-1}$, Murray et al. (2011) found that the freezing of droplets containing kaolinite $(\mathrm{KGa}-\mathrm{lb})$ was consistent with a stochastic model which required no interparticle variability. Broadley et al. (2012) used the same instrument with the mineral dust NX-illite and found that under isothermal conditions nucleation continued with time. Similarly, Welti et al. (2012), using an ice nucleation chamber to test their kaolinite sample (Fluka), found that the fraction of droplets frozen increased with increasing residence time; the authors also found that a factor of 10 change in residence time had the same effect on the fraction frozen as a temperature change of $1 \mathrm{~K}$. Wilson and Haymet (2012) have shown that repeated freezing and thawing cycles for a single droplet results in a distribution of freezing temperatures. The width of this distribution varies for different droplets and different materials, potentially indicating a range of time-dependent behaviour. More recently, Wright and Petters (2013) performed a series of freeze-thaw simulations and found that the mean variation in freezing temperature for their ensemble of droplets was dependent on the slope of the nucleationrate coefficient $\mathrm{d} \ln \left(J_{\mathrm{s}}\right) / \mathrm{d} T$, with cooling rate and INP surface area having little effect on the observed variation. Wright et al. (2013) tested a range of INP species and found variability in their cooling-rate dependence. For the minerals kaolinite, and montmorillonite, along with flame soot, the median freezing temperature of a droplet population decreased by $\sim 3 \mathrm{~K}$ upon a factor of $\sim 100$ increase in cooling rate. Conversely, the bacterial-based species Icemax ${ }^{\mathrm{TM}}$ showed no change for the same increase in cooling rate.

In summary, the stochastic, or probabilistic, nature of nucleation in some materials is more important or more apparent than in others and is rarely quantified. In order to fully understand the impact of different INP species and populations on clouds it is important to both fundamentally understand the nucleation mechanism and correctly represent this process in an efficient framework for use in cloud resolving models (CRMs).

The main objective of the work presented in this paper is to develop a framework that can be used to describe the time dependence of nucleation as well as the interparticle variability inherent to many nucleating materials. In this study we use a multiple-component stochastic model to establish the key relationships between the nucleation-rate coefficient of an INP and its observable time-dependent behaviour, which are then captured in a simple framework. This framework bears some resemblance to the empirically derived modified singular description presented by Vali (1994), but here we link the term describing the residence-time and cooling-rate dependence to the temperature dependence of the nucleation-rate coefficient. We then go on to use this framework to analyse several experimental data sets and discuss the implications for modelling ice nucleation in cloud models. For a description of the terms used throughout the text see Appendix A. 


\subsection{Immersion mode freezing models}

\subsubsection{The single-component stochastic freezing model}

Nucleation is thought to be a process where random fluctuations in ice-like clusters within a supercooled droplet result in a freezing event only if a cluster reaches a critical size. For homogeneous nucleation, the probability of a critical cluster forming rapidly increases with decreasing temperature (Stan et al., 2009; Murray et al., 2010). Additionally, the probability is increased for both larger droplet volumes and longer timescales. The inclusion of particles that can serve as INPs provide a surface which favours cluster formation, and therefore catalyse nucleation. The probability of a droplet freezing in this mode is a stochastic, time-dependent process with the temperature-dependent nucleation-rate coefficient $J_{\mathrm{S}}(T)$ expressed per unit surface area, per unit of time. In the singlecomponent stochastic freezing model it is assumed that every INP within a population can be described with the same function of $J_{\mathrm{S}}(T)$, which is consistent with nucleation by some materials including the mineral kaolinite (Murray et al., 2011) and silver iodide (Heneghan et al., 2001). Classical nucleation theory $(\mathrm{CNT})$ can be used to link $J_{\mathrm{S}}(T)$ to a conceptual contact angle, $\theta$, which is defined as the angle between the particle and ice cluster and is used as a measure of how efficiently a material nucleates ice.

\subsubsection{Singular freezing models}

Singular or deterministic models have been developed in light of the observation that the variability in freezing temperatures for an entire population of droplets in a cooling experiment can be significantly higher than that of a single droplet upon multiple freeze-thaw cycles (e.g. Vali, 2008). The range of freezing temperatures can also be much greater than the shift in temperature observed for a change of cooling rate. These observations have been used to argue that the time dependence of nucleation is of secondary importance in comparison to the interparticle variability in atmospheric aerosol (Vali, 2008). The reason why there is such strong interparticle variability in ice nucleating ability is very poorly understood, but could arise for a number of reasons: inhomogeneity of surface properties such as cracks, grain boundaries or pores have been shown to preferentially trigger nucleation (Pruppacher and Klett, 1997); a complex ice nucleating population with multiple constituent INP species, such as may exist within soil, could also present a range of nucleating efficiency within a single population (Conen et al., 2011; Atkinson et al., 2013); and small inclusions of a very active material, such as lead containing nanoparticles, can dominate and thus determine the ice nucleating ability of larger "host" particles (Cziczo et al., 2009). The concept of active sites has been introduced to describe this heterogeneity in ice nucleating ability in many samples, and singular freezing models have been developed to link this variable distribution to the freezing probability (Levine, 1950; Vali, 1971; Connolly et al., 2009; Sear, 2013). Nucleation on active sites, whatever their physical form, is a stochastic process (as will be discussed in Sect. 1.13 below), but within the singular model it is assumed that a particle or active site on that particle will trigger ice nucleation at a specific temperature independent of time. An advantage of this simplifying assumption is that the varying ice nucleating efficiency of an INP population or species can be represented as a simple function of temperature.

\subsubsection{Multiple-component freezing models}

In order to describe both the stochastic nature of ice nucleation and the varying efficiency of INPs in a physically based framework, a number of multiple-component freezing models have been developed. These descriptions use a distribution of sites or droplets displaying a range of nucleating characteristics to define the ice nucleating variability. Each component is assumed to approximate to a single-component model with a single function describing the nucleation-rate coefficient against temperature.

Marcolli et al. (2007) used a variety of probability density functions (PDFs) to represent populations of particles, each characterised by a particular contact angle $(0 \leq \theta \leq \pi)$, in order to fit CNT to their immersion freezing data. This was then extended to include an active site distribution, which assumed that a single INP may have multiple nucleation sites on its surface, determined by the probability of an active site occurring per contact angle. A proportion of nucleating surface area per contact angle was then calculated assuming a standard size for a single active site; thus, larger particles will be more likely to contain sites of better nucleating ability than smaller particles. Lüönd et al. (2010) used a similar method to reconcile their experimental data. A multiplecomponent framework capable of describing both internally and externally mixed populations was presented by Murray et al. (2011). This was extended by Broadley et al. (2012) into the multiple-component stochastic model (MCSM), which replaced CNT with a simple function to describe $J_{\mathrm{S}}(T)$ for each component. In their study this function was systematically adjusted using a Gaussian distribution to represent a population with varying droplet freezing ability and is discussed in more detail in Sect. 2. The "soccer ball model" was developed by Niedermeier et al. (2011) using a similar approach to Marcolli et al. (2007): in their description each particle is divided into a number of sites or patches, with each site randomly assigned a contact angle $(0 \leq \theta \leq \pi)$ from a Gaussian distribution. It can be seen that having a small number of sites per INP will result in a population with diverse ice nucleating ability, whereas more sites will increase the probability of a specific site occurring per INP, so that the population tends towards a uniform nucleating ability. More recently, Wright and Petters (2013) and Wright et al. (2013) 
used a similar description to Broadley et al. (2012) to simulate cooling and freeze-thaw experiments.

All of these multiple-component models can be used to describe the interparticle variability of ice nucleating efficiency within a population, and also the fundamental stochastic nature of ice nucleation. However, a significant increase in complexity is introduced through the treatment of separate populations and PDFs. Due to this, their use in CRMs is limited. Clearly, a framework is required that can adequately describe variable ice nucleating ability and stochastic behaviour in a computationally efficient way.

\section{The multiple-component stochastic model (MCSM)}

The MCSM, presented in Broadley et al. (2012), divides a population of particles, or nucleation sites, into subpopulations of equally efficient entities. Each subpopulation can then be treated as a single component with a uniform nucleating behaviour allowing the use of the single-component stochastic freezing model; the summation of these populations then represents the entire population. Assuming each droplet contains a single INP with surface area $A\left(\mathrm{~cm}^{2}\right)$ we can calculate the number of droplets that will freeze in a time increment $\delta t$ at temperature $T$ for a single component, denoted by $i$ :

$n_{\text {frozen }, i}=n_{\text {liquid }, i}\left(1-\exp \left(-J_{\mathrm{s}, i}(T) \cdot A_{i} \cdot \delta t\right)\right)$,

where $n_{\text {liquid, } i}$ is the number of liquid droplets at the beginning of the time step, $n_{\text {frozen, } i}$ is the number of frozen droplets, and $J_{\mathrm{s}, i}(T)$ is the nucleation-rate coefficient $\left(\mathrm{cm}^{-2} \mathrm{~s}^{-1}\right)$. Upon subsequent steps the number of available droplets is adjusted so that $n_{\text {liquid, } i+1}=n_{\text {liquid, } i}-n_{\text {frozen }, i}$. The exponential term describes the fractional probability $P_{\text {NOT }}$ of an event not happening, where $P_{\text {NOT }} \rightarrow 1$ represents an increasing probability that no freezing event will occur. For this study we use a simple linear temperaturedependent function to define $J_{\mathrm{s}, i}(T)$ of a single component following Broadley et al. (2012) and Wright and Petters (2013):

$\ln J_{\mathrm{s}, i}(T)=-\lambda_{i} T+\varphi_{i}$,

where $-\lambda_{i}$ represents the gradient of $\ln J_{\mathrm{s}, i}(T)$ and $\varphi_{i}$ the relative nucleating efficiency of the component. Others have used CNT to describe the temperature dependence of $J_{\mathrm{s}, i}(T)$ (Marcolli et al., 2007; Lüönd et al., 2010; Niedermeier et al., 2011), but measured nucleation coefficients approximate to Eq. (2) over the range of freezing temperatures observed during a single freezing experiment (typically $<10 \mathrm{~K}$ ) (Kashchiev et al., 2009; Stan et al., 2009; Ladino et al., 2011; Murray et al., 2010, 2011).

In order to extend Eq. (2) to multiple-component systems, each subpopulation, behaving as an independent single component, is characterised by a specific $\varphi_{i}$ and then
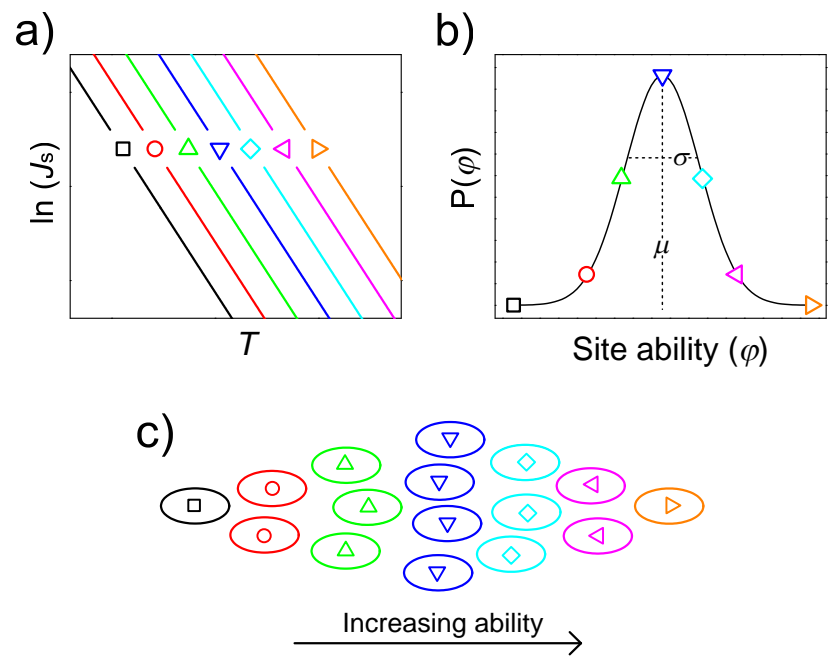

Figure 1. Principles of the multiple-component stochastic model. Each symbol represents a subpopulation approximated by a singlecomponent system, as shown in (a), with gradient $-\mathrm{d} \ln \left(J_{S, i}\right) / \mathrm{d} T=$ $\lambda$ and intercept $\varphi$ (proxy for nucleating efficiency). The probability of occurrence for each component, characterised by $\varphi$, is determined using a statistical distribution, as depicted in (b), with a mean $\mu$ and standard deviation $\sigma$. Applying this probability to a population of droplets results in an ensemble of droplets exhibiting a range of nucleating efficiencies as in (c).

weighted using a PDF to calculate a probability of occurrence $P\left(\varphi_{i}\right)$. Thus, the number of droplets in each subpopulation is $n_{\text {liquid, } i}=N \times P\left(\varphi_{i}\right)$, where $N$ is the total number of droplets in the simulation. Although there is evidence for multiple components, the distribution of such components is not currently known and difficult to infer. Therefore, for simplicity, a Gaussian distribution was used following previous studies (Niedermeier et al., 2010; Broadley et al., 2012; Wright and Petters, 2013), characterised by a mean $\mu$ and standard deviation $\sigma$ (see Fig. 1). The MCSM can now be defined by summing the number of droplets frozen in each subpopulation for a given time increment:

$N_{\text {frozen }}=\sum_{i=1}^{n} n_{\text {liquid }, i}\left(1-\exp \left(-J_{\mathrm{s}, i}(T) \cdot A_{i} \cdot \delta t\right)\right)$.

To investigate the sensitivity of the MCSM to time dependence (manifesting as a cooling-rate and residence-time dependence) an idealised box model was used to represent an immersion mode, droplet freezing experiment under constant cooling or isothermal conditions in which droplet volume was assumed to be constant with no condensational growth or evaporation. Freezing events were assumed to only occur within a single time step and within the bulk volume. Additionally, freezing of one droplet was assumed to have no effect on the remaining liquid population. 


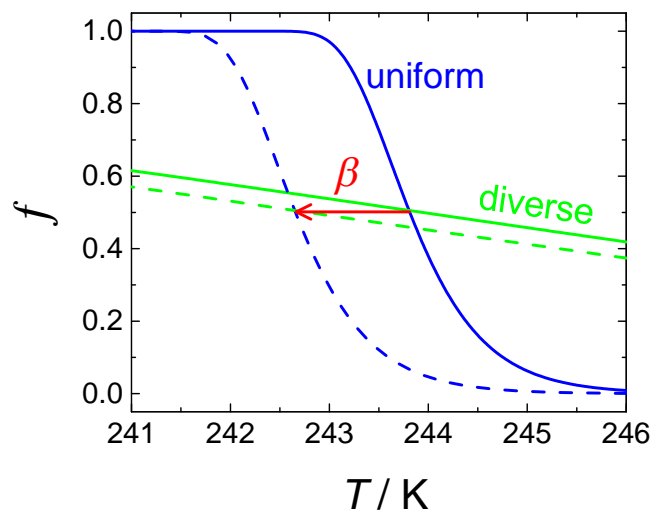

Figure 2. Illustration of how the systematic shift in temperature $(\beta)$ observed for a change in cooling rate is independent of the variability in ice nucleating ability. $f(T)$ curves shown are for a uniform $(\sigma=0.01)$ and diverse $(\sigma=20)$ INP population where $\lambda=2 \mathrm{~K}^{-1}$, and cooled at constant rates of $1 \mathrm{~K} \mathrm{~min}^{-1}$ (solid line) and $10 \mathrm{~K} \mathrm{~min}^{-1}$ (dashed line). $\beta$ corresponds to the shift in temperature $(\mathrm{K})$ observed when $50 \%$ of the droplets have frozen.

\section{Deriving a new immersion mode framework}

\subsection{Cooling-rate dependence}

In these simulations we look at the sensitivity of the MCSM to changes in cooling rate. The aim is to identify the variables that control the cooling-rate dependent behaviour of a population of droplets. On inspection of Eq. (3) it is evident that for a constant finite negative increment $\delta T$, an increase in cooling rate results in a similar decrease in time $\delta t$, and therefore a decrease in the probability of a freezing event occurring between $T$ and $T+\delta T$. This is manifested in the number of droplets freezing per $\delta T$ and results in the entire cumulative fraction frozen curve shifting to lower temperatures. This is demonstrated in Fig. 2, with two simulated populations of droplets: one with a uniform INP distribution (a single value of $\varphi_{i}$ ) and the other with a diverse INP distribution (broad range of $\left.\varphi_{i}\right)$. Both populations have $\lambda=2 \mathrm{~K}^{-1}$ where $\lambda$ is defined as $-\operatorname{d} \ln \left(J_{\mathrm{s}, i}\right) / \mathrm{d} T$ (i.e. the temperature dependence of the nucleation-rate coefficient for each component). The simulated droplets were cooled at 1 and $10 \mathrm{~K} \mathrm{~min}^{-1}$. Figure 2 illustrates how the shift in temperature $(\beta)$ for a change in cooling rate is independent of the distribution of $\varphi_{i}$. The independence of $\beta$ to the distribution of $\varphi_{i}$ has been further investigated using a series of droplet cooling simulations where all the free variables in the MCSM were allowed to vary between runs, with the corresponding values shown in Table 1. The results from these simulations, shown in Fig. 3, suggest that the only characteristic of the INP population required to quantify its cooling-rate dependence is $\lambda$. This is a similar conclusion to Broadley et al. (2012) and Wright and Petters (2013).

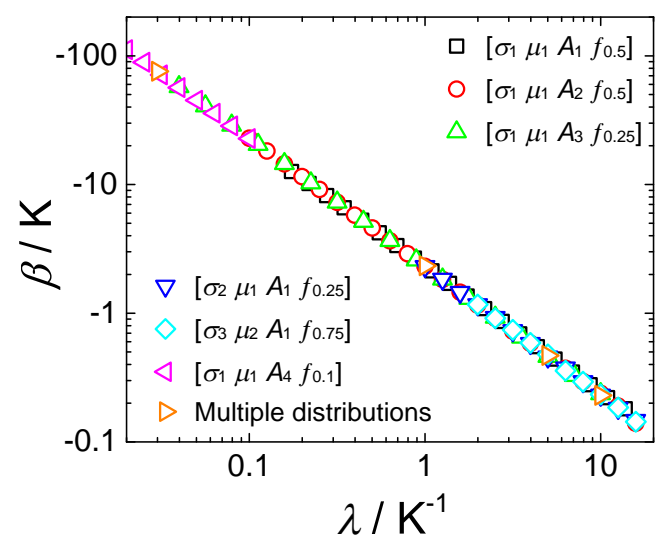

Figure 3. A direct relationship between $\lambda\left(-\mathrm{d} \ln \left(J_{\mathrm{s}, i}\right) / \mathrm{d} T\right)$ and $\beta$ (the shift in freezing temperature upon a factor of 10 change in cooling rate) is observed for all droplet cooling simulations. For each set of runs $\lambda$ was systematically increased whilst the following variables were set: mean $(\mu)$ and standard deviation $(\sigma)$ of the PDF, surface area of particle per droplet $(A)$, and the fraction at which the change in temperature was calculated $(f)$. More information can be found in Table 1.

This result can be understood by rearranging Eq. (1) to describe the change in temperature required to attain a specific cumulative frozen fraction for a given change in cooling rate (see Supplement for the full derivation). For a given population of droplets containing an immersed INP characterised by the function $J_{\mathrm{S}}(T)$, the total fraction of droplets frozen $f\left(n_{r}\right)=n_{\text {frozen }} / N_{\text {liquid }}$ upon cooling from $T_{0}$ to $T_{n_{r}}$ in $n_{r}$ steps, where $N_{\text {liquid }}$ is the number of droplets at $T_{0}$, can be described as:

$$
\begin{gathered}
f\left(n_{r}\right)=1-\prod_{k=0}^{n_{r}}\left(\exp -J_{\mathrm{s}}\left(T_{k}\right) \cdot A \cdot \delta t\right)= \\
1-\exp \left(-\sum_{k=0}^{n_{r}} J_{\mathrm{s}}\left(T_{k}\right) \cdot A \cdot \delta t\right),
\end{gathered}
$$

where $n_{r}$ denotes the total number of model steps using a cooling rate $r$, and $\delta t$ is the time between steps $k$ and $k+1$. As in Eq. (1) the exponential term essentially describes the cumulative probability of a freezing event not occurring in $n_{r}$ time steps, and can be expanded so that $J_{\mathrm{s}}\left(T_{k}\right)=J_{\mathrm{S}}\left(T_{0}\right) \times$ $(\exp (-\lambda \delta T))^{k}$. By substituting Eq. (2) into Eq. (4) we can explicitly represent the nucleation-rate coefficient:

$$
f\left(n_{r}\right)=1-\exp \left(-A \cdot \delta t \cdot J_{\mathrm{s}}\left(T_{0}\right) \sum_{k=0}^{n_{r}}(\exp (-\lambda \delta T))^{k}\right) .
$$

The summation term can be removed using a geometric summation of series formula. Once rearranged we have a formula to calculate the temperature $T_{f(n)}$ at which a specific fraction 
Table 1. The range of MCSM variables used for droplet cooling simulations in Fig. $3: \lambda$ is $-\operatorname{dln}\left(J_{\mathrm{s}, i}\right) / \mathrm{d} T ; \mu$ and $\sigma$ are the mean and standard deviation of the PDF used to constrain the occurrence of each component with "formula" referring to $\mu=240 \lambda+14.8$; surface area of immersed INP per droplet $A$; and the fraction $f$ at which the change in temperature $\left(\Delta T=\left(f_{r_{1}}\right)-T\left(f_{r_{2}}\right)\right)$ for a change in cooling rate $r$ is calculated. All simulations were performed at cooling rates of 1 and $10 \mathrm{~K} \mathrm{~min}^{-1}$.

\begin{tabular}{lllrr}
\hline Gradient $\lambda / \mathrm{K}^{-1}$ & PDF mean $\mu$ & PDF width $\sigma$ & Surface area $A$ & Fraction $f$ \\
\hline $0.2 \leq \lambda \leq 14$ & formula & 1 & $1 \times 10^{-7} \mathrm{~cm}^{2}$ & 0.5 \\
$0.1 \leq \lambda \leq 16$ & formula & 0.1 & $5 \times 10^{-7} \mathrm{~cm}^{2}$ & 0.5 \\
$0.04 \leq \lambda \leq 10$ & formula & 1 & $10 \times 10^{-7} \mathrm{~cm}^{2}$ & 0.25 \\
$1 \leq \lambda \leq 16$ & formula & 5 & $1 \times 10^{-7} \mathrm{~cm}^{2}$ & 0.25 \\
$2 \leq \lambda \leq 16$ & formula +10 & 10 & $1 \times 10^{-7} \mathrm{~cm}^{2}$ & 0.75 \\
$0.02 \leq \lambda \leq 0.1$ & formula & 1 & $1 \times 10^{-7} \mathrm{~cm}^{2}$ & 0.1 \\
0.03 & $\mu_{1}=9, \mu_{2}=12$ & $\sigma_{1}=0.1, \sigma_{2}=2$ & $1 \times 10^{-7} \mathrm{~cm}^{2}$ & 0.5 \\
1.0 & $\mu_{1}=255, \mu_{2}=265$ & $\sigma_{1}=1, \sigma_{2}=2$ & $1 \times 10^{-7} \mathrm{~cm}^{2}$ & 0.5 \\
5.0 & $\mu_{1}=1255, \mu_{2}=1260$ & $\sigma_{1}=1, \sigma_{2}=5$ & $1 \times 10^{-7} \mathrm{~cm}^{2}$ & 0.5 \\
10.0 & $\mu_{1}=2455, \mu_{2}=2465$, & $\sigma_{1}=1, \sigma_{2}=1$, & $1 \times 10^{-7} \mathrm{~cm}^{2}$ & 0.5 \\
& $\mu_{3}=2460$ & $\sigma_{3}=5$ & & \\
\hline
\end{tabular}

frozen is reached:

$$
\begin{aligned}
& T_{f(n)}=n_{r} \delta T= \\
& \ln \left[1-\left(\frac{-\ln \left(1-f\left(n_{r}\right)\right) \cdot(1-\exp (-\lambda \delta T))}{A \cdot \delta t \cdot J_{\mathrm{s}}\left(T_{0}\right)}\right)\right] \frac{1}{-\lambda}-1,
\end{aligned}
$$

where $\delta T$ is the change in temperature between steps $k$ and $k+1$. A change in cooling rate from $r_{1}$ to $r_{2}$ results in a change in the number of steps $\Delta n_{r}$ to reach fraction $f$ where $f=f_{n, r_{1}}=f_{n, r_{2}}$ and therefore a change $\Delta T_{f}$ :

$\Delta T_{f}=n_{r_{2}} \delta T-n_{r_{1}} \delta T=\ln \left(\frac{C \cdot A \cdot \delta t_{r_{2}} \cdot J_{\mathrm{s}}\left(T_{0}\right)}{C \cdot A \cdot \delta t_{r_{1}} \cdot J_{\mathrm{S}}\left(T_{0}\right)}\right) \cdot \frac{1}{-\lambda}$,

where $\delta T$ is constant for both cases, $\delta t$ is dependent on the cooling rate, and $C=-\ln (1-f) \times(1-\exp (-\lambda \delta T))$. Cancelling terms in Eq. (7) and substituting $r_{1}=\delta T / \delta t_{r_{1}}$ and $r_{2}=\delta T / \delta t_{r_{2}}$ provides a formula for the change in temperature, $\beta_{\mathrm{cool}}$, observed at a specific fraction frozen for a given change in cooling rate:

$\Delta T_{f}=\beta_{\mathrm{cool}}=\frac{1}{\lambda} \ln \left(\frac{r_{1}}{r_{2}}\right)$.

Equation (8) is consistent with the results shown in Figs. 2 and 3; i.e. the systematic shift in cumulative fraction frozen for a change in cooling rate is only dependent on $\lambda$. If we assume that all components in a diverse species are characterised by a single value of $\lambda$ this also holds true. Using observations by Vali and Stansbury (1966), Vali (1994) empirically found a similar relationship where $\beta_{\mathrm{cool}}=0.66 \times$ $\log _{10}(|r|)$. In our independently derived expression, we take the additional step of linking $\beta$ to $\lambda$, which offers a physical insight to the properties of a particular ice nucleating material; i.e. the empirical relationship from Vali (1994), above, relates to the gradient of the species $-\operatorname{dln}\left(J_{\mathrm{s}, i}\right) / \mathrm{d} T$ so that the distilled water droplets used in the study by Vali and Stansbury (1966) are characterised by the gradient $\lambda=3.5 \mathrm{~K}^{-1}$.

\subsection{Residence-time dependence}

In addition to droplet freezing experiments where droplets are cooled at some rate, other experiments (e.g. those using continuous flow diffusion chambers) involve exposing particles to a constant temperature for a defined period of time. In this section we show how measurements made with different residence times under isothermal conditions in such instruments can be reconciled by extending the $\lambda$-based formula presented in the previous section. Using $r=\delta T / t$, the relative change in cooling rate described by $\ln \left(r_{1} / r_{2}\right)$ can also be expressed as a relative change in time $\ln \left(t_{2} / t_{1}\right)$ :

$\beta_{\text {iso }}=\frac{1}{\lambda} \ln \left(\frac{t_{2}}{t_{1}}\right)$,

where $\beta_{\text {iso }}$ is the shift in temperature required to produce the same frozen fraction in two isothermal experiments with duration times of $t_{1}$ and $t_{2}$.

\section{$3.3 \sigma_{T_{\text {freeze }}}$ in freeze-thaw experiments}

In freeze-thaw experiments, single or populations of droplets are subjected to repeated cycles of freezing and thawing (Vali and Stansbury, 1966; Durant and Shaw, 2005; Vali, 2008; Fornea et al., 2009; Wright et al., 2013). For each cycle the freezing temperature $T_{\text {freeze }}$ is determined, and used to infer the stochastic nature of the tested material. A freezethaw experiment can be simulated when it is realised that one droplet being frozen $n$ times at a cooling rate $r$ is equivalent to $n$ identical droplets being frozen a single time at a rate $r$. A single-component system where $\varphi$ equals the median $T_{\text {freeze }}$ provides a population of identical droplets, which can be used with the MCSM to simulate a single cooling experiment. Applying a prescribed $n$ droplets to the resulting $f(T)$ curve provides the temperature at which each consecutive droplet freezes. These temperatures correspond to $T_{\text {freeze }}$ 
values from $n$ freeze-thaw cycles, and therefore the standard deviation in $T_{\text {freeze }}$ can be determined, hereafter named $\sigma_{T_{\text {freeze }}}$ (after Wright and Petters, 2013). A series of simulations were performed using the MCSM where the median $T_{\text {freeze }}$ and $\lambda$ were varied. A direct relationship between $\lambda$ and $\sigma_{T_{\text {freeze }}}$ was found and is described as:

$\sigma_{T_{\text {freeze }}}=\frac{1.2691}{\lambda}$.

In a single-component system a variation in cooling rate will only result in a change to the median freezing temperature (by $\beta \mathrm{K}$ ), therefore $\sigma_{T_{\text {freeze }}}$ is also independent of the freezethaw experiment cooling rate. Equation (10) bears a significant resemblance to the relationship presented by Wright and Petters (2013): $\sigma_{T_{\text {freeze }}}=1.21 \times \lambda^{-1.05}$.

\subsection{Reconciling droplet freezing data from different instruments and on different timescales}

Since nucleation is a stochastic process, differences in experimental timescale and experimental technique need to be reconciled. First we reconcile isothermal data with cooling experiments so they are consistent with each other. This can be achieved by equating the simulated fraction frozen using both methods at the same temperature:

$f_{\text {iso }}(T)=f_{\text {cool }}(T)$,

where "cool" denotes a cooling experiment simulation from $T_{0}=273.15 \mathrm{~K}$ and "iso" an isothermal experiment simulation at a temperature $T$. The fraction frozen during an isothermal simulation is calculated similarly to a cooling experiment except the temperature remains constant throughout; thus, we can use Eq. (4) to describe an isothermal simulation:

$f_{\text {iso }}(T)=1-\prod_{k=0}^{n_{\text {iso }}} \exp \left(-J_{\mathrm{s}}\left(T_{k}\right) \cdot A \cdot \delta t_{\text {iso }}\right)$,

$J_{\mathrm{S}}\left(T_{k}\right)=J_{\mathrm{S}}(T)$,

therefore,

$f_{\text {iso }}(T)=1-\exp \left(-J_{\mathrm{S}}(T) \cdot A \cdot \delta t_{\text {iso }} \cdot n_{\text {iso }}\right)$,

where $n_{\text {iso }}$ is the total number of time steps, $\delta t_{\text {iso }}$, for the isothermal simulation. Substituting Eqs. (14) and (4) into Eq. (11) yields:

$$
\begin{array}{r}
1-\exp \left(-J_{\mathrm{s}}\left(T_{n_{\text {cool }}}\right) \cdot A \cdot \delta t_{\text {iso }} \cdot n_{\text {iso }}\right)= \\
1-\exp \left(-\sum_{k=0}^{n_{\text {cool }}} J_{\mathrm{s}}\left(T_{k}\right) \cdot A \cdot \delta t_{\text {cool }}\right),
\end{array}
$$

which, when simplified gives the total time $\left(t_{\text {total }}\right)$ required for an isothermal experiment to reach the same fraction as a cooling experiment at temperature $T$ :

$\delta t_{\text {iso }} \cdot n_{\text {iso }}=t_{\text {total }, \text { iso }}\left(T_{n_{\text {cool }}}\right)=\frac{1}{J_{\mathrm{s}}\left(T_{n_{\text {cool }}}\right)} \sum_{k=0}^{n_{\text {cool }}} J_{\mathrm{s}}\left(T_{k}\right) \delta t_{\text {cool }}$.
Substituting in Eq. (2), after expanding as in Sect. 3.1, and rearranging yields:

$t_{\text {total,iso }}\left(T_{n_{\text {cool }}}\right)=\delta t_{\text {cool }} \sum_{k=0}^{n_{\text {cool }}}(\exp (\lambda \delta T))^{k}$.

Using a summation of series the summation term is removed and the formula can be simplified:

$t_{\text {total }, \text { iso }}\left(T_{n_{\text {cool }}}\right)=\frac{\delta t_{\text {cool }}}{1-\exp \left(\lambda \cdot \delta T_{\text {cool }}\right)}$.

A Taylor expansion of $\exp \left(\lambda \times \delta T_{\mathrm{cool}}\right)$ will result in the series $\left(1+\lambda \delta T_{\text {cool }}-1 / 2\left(\lambda \delta T_{\text {cool }}\right)^{2}+1 / 6\left(\lambda \delta T_{\text {cool }}\right)^{3} \ldots\right)$. When $\lambda \delta T_{\text {cool }} \gg 1 / 2\left(\lambda \delta T_{\text {cool }}\right)^{2}, \exp \left(\lambda \delta T_{\text {cool }}\right) \cong 1+\lambda \delta T_{\text {cool }}$.

This is satisfied when the simulation temperature step $\lambda \delta T_{\text {cool }} \ll 1$. We can then simplify this formula using $r_{\text {cool }}=\delta T_{\text {cool }} / \delta t_{\text {cool }}$, where $r_{\text {cool }}>0$, so that:

$t_{\text {total }, \text { iso }}\left(T_{n_{\text {cool }}}\right)=\frac{\delta t_{\text {cool }}}{\lambda \cdot r_{\text {cool }} \cdot \delta t_{\text {cool }}}=\frac{1}{\lambda \cdot r_{\text {cool }}}$.

Assuming that the nucleation-rate coefficient of a species is approximated by the functional form in Eq. (2), this gives the time required for an isothermal experiment to reach the same frozen fraction as in a cooling-rate experiment at a specific temperature. Again $\lambda$ (the gradient of the nucleation-rate coefficient) controls the time-dependent nature of immersion mode droplet freezing.

Now that isothermal and cooling experiments are reconcilable, artefacts introduced through the time-dependent behaviour of an INP in an experiment can be normalised to a standard rate $r_{\text {standard }}$, for which we have chosen $1 \mathrm{~K} \mathrm{~min}^{-1}$. For cooling experiments, replacing $r_{1}$ in Eq. (8) with $r_{\text {standard }}$ and $r_{2}$ with the experimental cooling rate $r$, in $\mathrm{K} \mathrm{min}^{-1}$, gives $\beta$ as a function of the absolute cooling rate:

$\beta(r)=\Delta T=\frac{1}{\lambda} \ln \left(\frac{1}{|r|}\right)$.

For isothermal experiments, replacing $r_{\text {cool }}$ with $r_{\text {standard }}$ in Eq. (19) gives the time required for an isothermal experiment to be comparable to a normalised cooling experiment. Substituting $t_{1}$ in Eq. (9) with $t_{\text {total }}$ in Eq. (19), and $t_{2}$ with the experimental residence time $t$, in seconds, gives $\beta$ as a function of residence time:

$\beta(t)=\Delta T=\frac{1}{\lambda} \ln \left(\frac{\lambda \cdot t}{60}\right)$.

Experimental data can then be modified and normalised using $T^{\prime}=T_{\text {experiment }}-\beta$, where $T^{\prime}$ is the normalised temperature, and $T_{\text {experiment }}$ the temperature of the experiment data point.

For an INP species characterised by a specific $\lambda$, this immersion mode framework, named the Framework for Reconciling Observable Stochastic Time-dependence (FROST), can be used to reconcile and normalise data obtained through cooling and isothermal experiments. 


\subsection{Incorporating the FROST framework into a singular model}

As discussed in Sect. 1.1.2, the singular freezing model is well suited to describing the interparticle variability of ice nucleating ability, but it does not describe the time-dependent nature of nucleation. The probability of a droplet freezing is often described by the active site density (Demott, 1995), $n_{\mathrm{S}}(T)$, (also called the ice active surface site density; Connolly et al., 2009; Murray et al., 2012; Hoose and Mohler, 2012) which describes the cumulative number of freezing events that can occur between $T_{0}$ and $T$ :

$f(T)=1-\exp \left(-n_{\mathrm{s}}(T) \cdot A\right)$.

Vali refers to a similar quantity (expressed per volume rather than surface area) as the cumulative nucleus spectrum (Vali and Stansbury, 1966; Vali, 1971, 2014). By rearranging Eq. (22) it can be seen that $n_{\mathrm{s}}(T)$ (in $\mathrm{cm}^{-2}$ ) is directly related to the cumulative fraction frozen:

$n_{\mathrm{S}}(T)=-\frac{\ln (1-f(T))}{A}$.

It is therefore apparent that a systematic shift in the cumulative fraction frozen, caused by a change in the cooling rate or residence time, results in a systematic shift in $n_{\mathrm{S}}(T)$ so that, upon incorporating Eq. (20) into Eq. (23), we find that for a specific cooling rate $r$ (where $r>0$ ),

$f(T, r)=1-\exp \left(-n_{\mathrm{s}}\left(T-\frac{\ln (|r|)}{-\lambda}\right) \cdot A\right)$.

The differentiation of $n_{\mathrm{s}}$ with respect to $T$ results in the function $k(T)$ that can be used to calculate the change in the fraction frozen occurring upon a lowering of $T$ :

$\Delta f(T, r)=1-\exp \left(-k\left(T-\frac{\ln (|r|)}{-\lambda}\right) \cdot A \cdot \Delta T\right)$,

where $k(T)$ is in units per square centimetre per kelvin $\left(\mathrm{cm}^{-2} \mathrm{~K}^{-1}\right)$. Equations (24) and (25) are consistent with the empirical "modified singular" equation presented by Vali (1994), but here we have linked the stochastic term to the temperature dependence of the nucleation-rate coefficient.

Similar equations can also be defined for isothermal experiments by incorporating Eq. (21) into Eq. (22) so that at a specific temperature, $T_{\text {iso }}$, and residence time in seconds, $t$,

$f(T, t)=1-\exp \left(-n_{\mathrm{s}}\left(T-\frac{1}{\lambda} \ln \left(\frac{\lambda \cdot t}{60}\right)\right) \cdot A\right)$.

Again, upon differentiation we obtain an equation for the change in fraction frozen upon a change in residence time from $t$ to $t+\Delta t$ :

$\Delta f(T, t)=1-\exp \left(-k\left(T-\frac{1}{\lambda} \ln \left(\frac{\lambda \cdot t}{60}\right)\right) \cdot A \cdot \frac{1}{-\lambda \cdot t} \Delta t\right)$,

where $\Delta t /(-\lambda \times t)$ has replaced $\Delta T$ through the incorporation of Eq. (19) into $\Delta T=-r / 60 \times \Delta t ; r$ is in kelvin per minute $\left(\mathrm{K} \mathrm{min}^{-1}\right)$ and $\Delta t$ in seconds.

\section{Testing the FROST framework}

In the previous section we presented the FROST framework which is a new immersion mode ice nucleation framework designed to represent both the interparticle variability of ice nucleating efficiencies and the stochastic (time-dependent) nature of nucleation. In this section the FROST framework will be tested using a combination of original experimental droplet freezing data and literature data for atmospherically relevant INPs obtained from a range of methods and instruments. The terminology here follows that of Vali (2014) in that experimental data are presented using the freezing rate $R$. A normalisation of $R$ to surface area $A$ is used to comment on the relationship between $R$ and the nucleation-rate coefficient $J_{\mathrm{s}}$, as well as whether the species behaves as a single- or multiple-component species.

\subsection{Kaolinite data (KGa-1b) from two cold-stage instruments}

In this example data from droplet freezing experiments on two cold-stage instruments, with a range of cooling rates, are combined to test the capability of the FROST framework. The first data set, referred to as PICOLITRE, is taken from Murray et al. (2011), hereafter referred to as M11. In their experiments micron-sized droplets containing known amounts of kaolinite (KGa-1b, Clay Mineral Society) mineral dust and supported on a hydrophobic surface, were cooled at constant rates on a cold stage coupled with an optical microscope. Each experiment was characterised by a specific cooling rate and weight fraction of mineral per droplet. For this study four data sets are used (experiments vii, viii, $i x$ and $x i$ in M11) corresponding to cooling rates (weight fractions) of 5.4 (0.0034), 9.6 (0.01), 0.8 (0.01) and $5.1(0.01) \mathrm{K} \mathrm{min}^{-1}$, respectively. For the second experimental data set, referred to as MICROLITRE, a different cold-stage instrument was used, which has been described previously (O'Sullivan et al., 2014; Whale et al., 2014). In this experiment $\sim 40$ droplets of $1 \mu \mathrm{L}$ volume containing known amounts of the same kaolinite sample as M11 (KGa-1b) were held on a hydrophobic surface and cooled at constant rates with freezing events recorded optically. Four experiments were performed at cooling rates of $0.1,0.2,0.5$, and $1.0 \mathrm{~K} \mathrm{~min}^{-1}$. All experiments were performed with a weight fraction of 0.01 , corresponding to a surface area of $1.178 \pm 0.3 \mathrm{~cm}^{2}$ per droplet calculated using a specific surface area of $11.8 \pm 0.8 \mathrm{~m}^{2} \mathrm{~g}^{-1}$ (M11). The uncertainty in surface area per droplet primarily arises from uncertainty in specific surface area measurements and droplet volume. The temperature uncertainty, arising from the temperature probe and observed range in melting temperatures, has been estimated by Whale et al. (2014) as $\pm 0.4 \mathrm{~K}$. Freezing data are limited to $T>252.65 \mathrm{~K}$, below which the substrate is observed to influence freezing behaviour.

Surface-area normalised freezing rates $(R / A)$ for the PICOLITRE and MICROLITRE experiments are shown in 

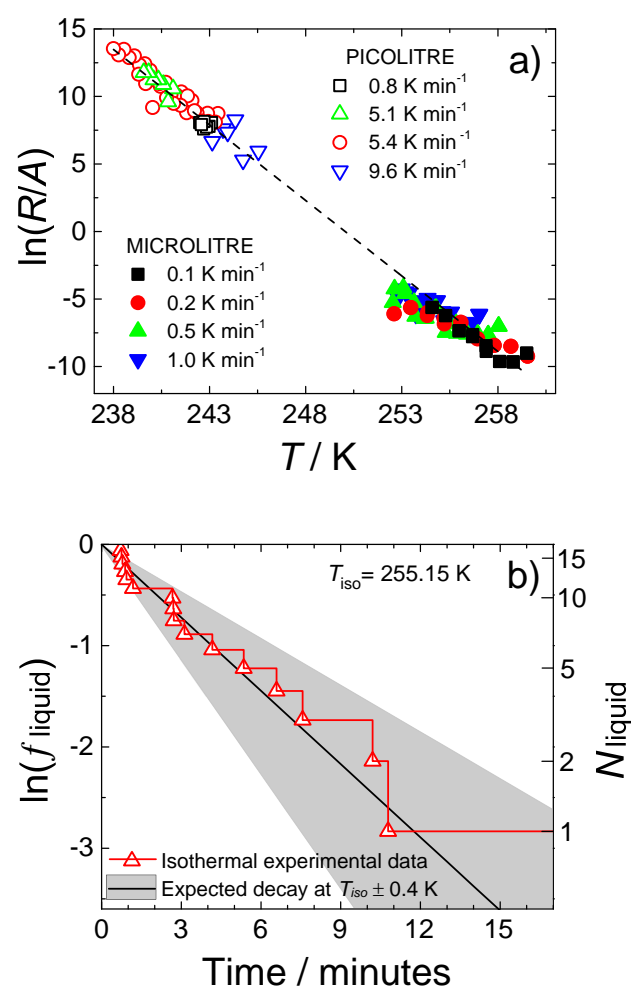

Figure 4. Droplet freezing data for kaolinite (KGa-1b). (a) shows freezing rates normalised to surface area, $R / A$, against temperature determined from droplet freezing experiments with a range of cooling rates. Open symbols represent PICOLITRE experiments from Murray et al. (2011) and closed symbols represent MICROLITRE experiments. The black dashed line shows a linear fit to all data $(\ln (R / A)=-1.12 T+280)$. Temperature uncertainty for the MICROLITRE data (not shown) is estimated at $\pm 0.4 \mathrm{~K}$, and uncertainty in $R / A$ (not shown) is estimated at -17 and $+25 \%$. (b) shows the exponential decay of liquid droplets during an isothermal experiment at $255.15 \mathrm{~K}$ together with a modelled experiment at the same temperature using the linear fit to all data in (a). The grey area follows the experimental uncertainty in $T$ around the modelled isothermal. The experiment duration was $17 \mathrm{~min}$, at which point one droplet remained unfrozen.

Fig. 4a. The larger droplets in the new MICROLITRE experiment contain significantly greater INP surface area per droplet than the PICOLITRE experiment, which increases the probability of freezing, resulting in higher freezing temperatures. The freezing rates plotted in Fig. 4a are derived using Eq. (1), hence the assumption in performing this analysis is that the species has a uniform INP distribution and behaves as a single-component system, and thus the normalised freezing rate $R / A$ is directly equivalent to the nucleation rate $J_{\mathrm{s}, i}$. However, at this stage we do not know if this assumption is valid.

In a single-component system the gradient $-\mathrm{d} \ln (R / A) / \mathrm{d} T$, named $\omega$ following Vali (2014), is equal to $\lambda$ (recall that $\left.\lambda=-\mathrm{d} \ln \left(J_{\mathrm{s}, i}\right) / \mathrm{d} T\right)$. If it were a multiple-component system then the slope $\omega$ will be smaller than $\lambda$ because an inappropriate model was used (i.e. $\omega$ is a lower limit to $\lambda$ ). For a set of data obtained at a single cooling rate it is impossible to say if it is a single- or multiple-component sample, further tests are required. M11 did this by performing isothermal experiments in addition to experiments at various cooling rates and showed that the values of $R / A$ derived from both experiment styles were consistent and concluded that nucleation by kaolinite $\mathrm{KGa}-1 \mathrm{~b}$ behaved as a single-component system below $246 \mathrm{~K}$ and therefore $R / A=J_{\mathrm{s}, i}$. We expand on this earlier analysis with additional data for kaolinite KGa$1 \mathrm{~b}$ at warmer temperatures and place it in the context of the FROST framework. To test whether the MICROLITRE data set is also consistent with a single-component system we performed an isothermal experiment, in addition to the experiments at various cooling rates.

The isothermal experiment, shown in Fig. 4b, was performed at $255.15 \mathrm{~K}$ with droplets containing a weight fraction 0.01 of KGa- $1 \mathrm{~b}$ particles. We have plotted the decay of liquid droplets expected based on a value of $J_{\mathrm{s}, i}$ at $255.15 \pm 0.4 \mathrm{~K}$ determined from the linear fit to $\ln (R / A)$ in Fig. 4a. The expected exponential decay matches the measured decay; this is consistent with a uniform species, and thus a single-component system. The derived $R / A$ values from experiments at cooling rates ranging from 0.1 to $1.0 \mathrm{~K} \mathrm{~min}^{-1}$ are shown in Fig. $4 \mathrm{a}$ and also show consistency with this system.

In Fig. 5 we place the data from the cooling experiments in the context of FROST. If the INP species can be characterised with a single $\lambda$ then the application of Eq. (20) will modify each data point by $T^{\prime}=T_{\text {experiment }}-\beta(r)$. With the correct value of $\lambda$ in the FROST framework, the data will converge onto the curve of a $1 \mathrm{~K} \mathrm{~min}^{-1}$ cooling experiment for the species tested. Figure $5 \mathrm{a}, \mathrm{b}$, and $\mathrm{c}$ show the fraction frozen $f(T), n_{\mathrm{s}}(T)$ values, and $R / A(T)$ values from Fig. $4 \mathrm{a}$, respectively. The $n_{\mathrm{S}}(T)$ values, derived using Eq. (23), depend on the cooling rate, with over a factor of 5 shift on changing the cooling rate by a factor of 10. On applying FROST with $\lambda=1.12 \mathrm{~K}^{-1}$ (thus assuming $\lambda=\omega$ from Fig. $4 \mathrm{a}$ ) both the modified $f\left(T^{\prime}\right)$ and $n_{\mathrm{s}}\left(T^{\prime}\right)$ data converge (Fig. $5 \mathrm{~d}$ and e, respectively). This additionally supports the claim that kaolinite $\mathrm{KGa}-1 \mathrm{~b}$ is well represented by a single-component system $\left(R / A=J_{\mathrm{s}, i}\right)$.

An interesting and potentially significant issue is raised by this study of nucleation by kaolinite as the linear fit to the two independent data sets in Fig. 4a is made over $20 \mathrm{~K}$ which is at odds with CNT. CNT predicts curvature in $\ln J_{\mathrm{s}}$ versus $T$ over tens of kelvin (Pruppacher, 1995). This might suggest that there is a flaw in CNT theory, or alternatively it may be the case that there are multiple INP populations which happen to give the appearance of a single-component system. However, the evidence presented here suggests that KGa- $1 \mathrm{~b}$ behaves as a single component, with consistent behaviour at high and low temperatures. This issue requires further study 

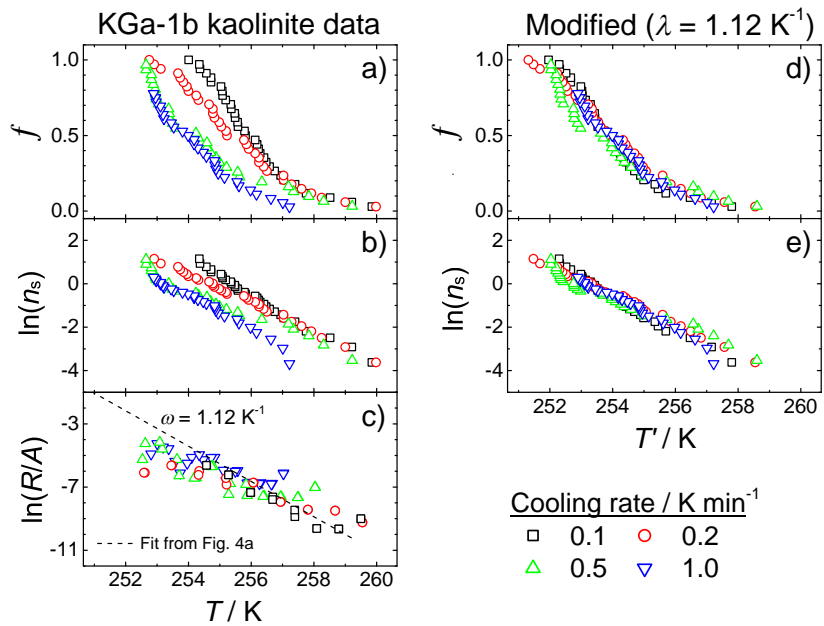

Figure 5. The freezing of droplets containing kaolinite (KGa-1b) in cooling experiments (MICROLITRE). (a) Raw $f(T)$ data, (b) derived $R / A(T)$, (c) $n_{\mathrm{S}}(T)$ values, (d) the corresponding normalised $f\left(T^{\prime}\right)$ data, and (e) normalised $n_{\mathrm{S}}\left(T^{\prime}\right)$. Data were normalised using the value of $\lambda$ determined directly from the linear fit to $\ln (R / A)$ against $T$ in Fig. 4a and reproduced in (c). Temperature and $R / A$ uncertainty is as in Fig. 4. Uncertainty in $n_{\mathrm{S}}$ (not shown) is estimated as $\pm 20 \%$.

to understand this potentially important finding, but is beyond the focus of this paper.

While nucleation by this kaolinite sample can be treated as a single component, this does not necessarily mean that this sample is uniform (i.e. there is no interparticle variability) because there are many particles per droplet in the experiment. It is possible, but unlikely, that droplets contain a distribution of particles with diverse ice nucleating abilities, but where freezing in all droplets happens to be controlled by particles with similar ice nucleating activity. This is very unlikely given that the number of kaolinite particles in the PICOLITRE experiments ranges from just a few tens to tens of thousands and all produce consistent values of $J_{\mathrm{s}}$ (M11). In contrast, the Fluka kaolinite sample used by Welti et al. (2012), which is known to contain particles of very efficient feldspar (Atkinson et al., 2013), is a diverse species (as will be demonstrated in Sect. 4.3).

In summary, kaolinite $\mathrm{KGa}-1 \mathrm{~b}$ from the clay mineral society is an example of a material which most likely has approximately uniform ice nucleating properties and can be described with a single-component stochastic model.
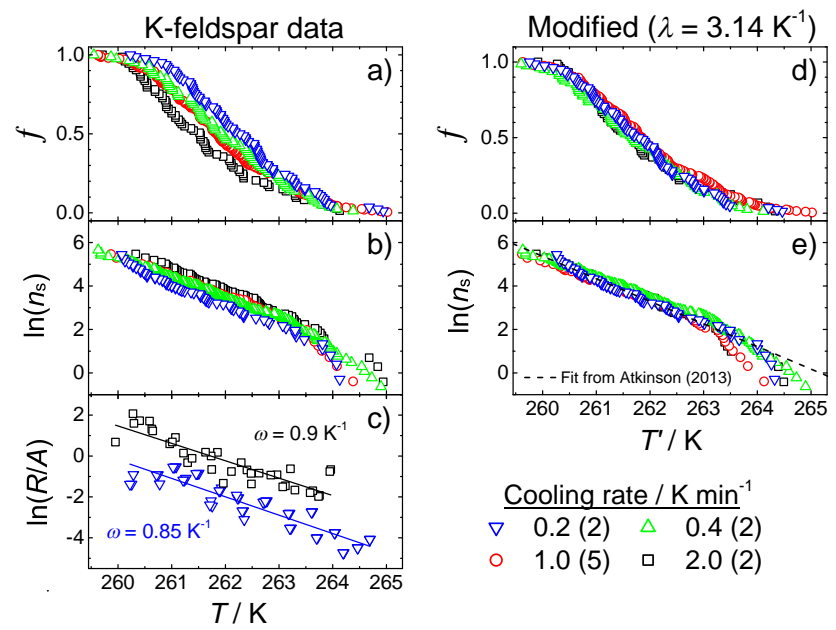

Figure 6. The freezing of droplets containing K-feldspar for a range of cooling rates. Layout as in Fig. 5. Brackets beside the cooling rates indicate the number of experiments performed and subsequently combined. Linear fits to derived $\ln (R / A)$ values for runs at 0.2 and $2.0 \mathrm{~K} \mathrm{~min}^{-1}$ are shown as solid lines in (c) resulting in $\omega=0.85$ and $0.9 \mathrm{~K}^{-1}$, respectively. Modified $n_{\mathrm{S}}\left(T^{\prime}\right)$ data were minimised in order to determine a value of $\lambda$ that best describes the cooling-rate dependence, resulting in $\lambda=3.4 \mathrm{~K}^{-1}$. In this example $\omega \neq \lambda$ suggesting that K-feldspar is a diverse INP species and behaves as a multiple-component system. The dashed line in (e) is a fit to K-feldspar experimental data taken from Atkinson et al. (2013). Temperature uncertainty is as in Fig. 4, and uncertainty in $n_{\mathrm{S}}$ and $R / A$ (not shown) is estimated as $\pm 25 \%$.

\subsection{K-feldspar data from a cold-stage instrument}

In this example we investigate and determine the coolingrate dependence of K-feldspar using the microlitre droplet instrument as in the previous example. K-feldspar was recently shown to be the most important mineral component of desert dusts for ice nucleation (Atkinson et al., 2013). In these experiments $\sim 40$ droplets of $1 \mu \mathrm{L}$ volume were cooled at constant rates of $0.2,0.4,1.0$ and $2.0 \mathrm{~K} \mathrm{~min}^{-1}$ on a hydrophobic surface. Each droplet contained a weight fraction 0.001 of K-feldspar, corresponding to a surface area of $1.85 \times 10^{-2} \pm 0.004 \mathrm{~cm}^{2}$ calculated using a specific surface area of $1.86 \mathrm{~m}^{2} \mathrm{~g}^{-1}$ (Whale et al., 2014).

Similar to the previous example, Fig. 6a, b, and c show the experimental fraction frozen data $f(T)$, and derived $n_{\mathrm{S}}(T)$ and $R / A(T)$ values, respectively. For the $0.2,0.4$ and $2.0 \mathrm{~K} \mathrm{~min}^{-1}$ curves two separate experiments were performed and for the $1.0 \mathrm{~K} \mathrm{~min}^{-1}$ curve five experiments were performed. A systematic shift in $f(T)$ outside of instrumental error $( \pm 0.4 \mathrm{~K})$ can be seen for the experiments at 0.2 and $2 \mathrm{~K} \mathrm{~min}^{-1}$, which indicates that there is a cooling-rate dependence for nucleation by K-feldspar.

We now need to test if these data are consistent with a single- or multiple-component system. Normalised freezing rates, $R / A$, for the 0.2 and $2.0 \mathrm{~K} \mathrm{~min}^{-1}$ runs are shown in 
Fig. 6c. If K-feldspar behaved as a single-component system then the two data sets would fall onto the same line, as they do for kaolinite in Fig. 4a. However, they do not fall on the same line; the $R / A$ values are significantly different between the two cooling rates, hence this suggests that $\mathrm{K}$-feldspar is a diverse species and requires a multiple-component model to describe its freezing behaviour. In this case Eq. (1) should not be used to derive values of nucleation-rate coefficients since $R / A \neq J_{\mathrm{s}, i}$.

As stated in the previous section, with the correct value of $\lambda$ in the FROST framework, the modified data will converge onto a single curve. Therefore, in order to determine the value of $\lambda$, a procedure was followed where $\lambda$ was iteratively varied until $n_{\mathrm{S}}\left(T^{\prime}\right)$, where $T^{\prime}=T_{\text {experiment }}-\beta(r)$, converged onto a single curve (using Eq. 20). The best fit was determined by minimisation of the root-mean-square error (RMSE) between the data and a linear fit to $\ln \left(n_{\mathrm{s}}\right)$ for data where $T_{\text {experiment }} \leq 262.65 \mathrm{~K}\left(-10.5^{\circ} \mathrm{C}\right)$; this temperature was chosen to limit effects from anomalous high-temperature freezing events that are statistically unrepresentative of the INP species. This fitting procedure, with a RMSE value of 0.009 , resulted in $\lambda=3.4 \mathrm{~K}^{-1}$ and is shown in Fig. 6e. This value is significantly steeper than the gradients $\omega$ in Fig. 6c $\left(0.85\right.$ and $\left.0.9 \mathrm{~K}^{-1}\right)$. Recall that for kaolinite, the gradient $\omega$ was used to normalise the $n_{\mathrm{s}}$ values in Fig. 5e which suggests that kaolinite is a uniform species. For K-feldspar the fact that $\omega \neq \lambda$ (where $\lambda=-\operatorname{d} \ln \left(J_{\mathrm{s}, i}\right) / \mathrm{d} T$ ) shows that $\mathrm{K}$ feldspar exhibits a diverse nucleating ability across the population.

Figure 6e also includes the fit to K-feldspar data presented in Atkinson et al. (2013). In their study the surface area of $\mathrm{K}$-feldspar per droplet was increased by 2 orders of magnitude to examine the dependence of freezing rate on surface area and all experiments were performed at a cooling rate of $1 \mathrm{~K} \mathrm{~min}^{-1}$. The parameterisation from Atkinson et al. (2013), based on data with variable surface areas, is in good agreement with data from the present study.

An isothermal experiment was also performed at $T_{\text {iso }}=262.15 \mathrm{~K}$ with 20 droplets $(28$ froze during cooling to $T_{\text {iso }}$ ) containing a weight fraction 0.001 of K-feldspar (see Fig. 7). For a uniform species the decay of liquid droplets over time will be exponential (as was the case for kaolinite KGa-1b in Fig. 4b), whereas a diverse species will result in a non-exponential decay. Inspection of the data in Fig. 7 shows that the decay of liquid droplets was not exponential, again consistent with a diverse population of INPs. To highlight this, we have plotted the decay expected from the two limiting values of $R / A$ from Fig. $6 \mathrm{c}$ at $262.15 \mathrm{~K}$. The simulated decays, assuming a single-component system, clearly overpredict the rate of decay. We also simulate what we would expect for a diverse population where we use the MCSM to produce the expected decay of droplets. The MCSM was initially used as a fitting tool to obtain a distribution that best reproduced the entire normalised $f\left(T^{\prime}\right)$ data set in Fig. $6 \mathrm{~d}$, using the minimised value $\lambda=3.4 \mathrm{~K}^{-1}$ determined previ-

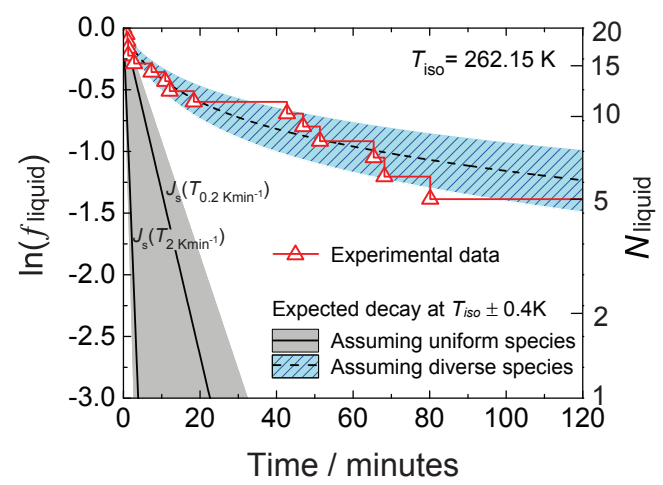

Figure 7. Decay of liquid droplets containing K-feldspar in an isothermal experiment at $T_{\text {iso }}=262.15 \mathrm{~K}$, and simulated experiments assuming a uniform and diverse distribution. For the uniform distribution $J_{\mathrm{S}}\left(T_{\text {iso }}\right)$ values were taken from Fig. 6a (thus assuming a single-component system where $J_{\mathrm{S}}=R / A$ ) and used with Eq. (1), resulting in a decay bounded by the range of $R / A$ between the two cooling rates of 0.2 and $2.0 \mathrm{~K} \mathrm{~min}^{-1}$. For the diverse simulation the MCSM was used with parameters determined through fitting to the normalised K-feldspar data set in Fig. 6: $\mu=890.5, \sigma=3.8$ (see Fig. 1), and $\lambda=3.4 \mathrm{~K}^{-1}$ (determined in Fig. 6). The shaded regions follow the instrument-based error of $\pm 0.4 \mathrm{~K}$ around $T_{\text {iso }}$. The triangular symbols indicate when freezing events occurred throughout the 120 min duration of the experiment.

ously. This distribution $(\mu=890.5, \sigma=3.8)$ was then used to simulate an isothermal experiment. These simulations included the initial cooling period required to reach the supercooled temperature. There is clear consistency between the diverse simulation and the experimental data. This again shows strong evidence that the K-feldspar sample used is a diverse species and would require a multiple-component system to describe its freezing behaviour.

This example is important as it illustrates that for a diverse INP species with multiple active components, the observed gradient $\omega$ of the derived $R / A(T)$ values from a single experiment does not characterise its stochastic behaviour. For these species a series of experiments at different cooling rates or residence times must be performed in order to determine the value of $\lambda$ that can be used to characterise its stochastic behaviour.

\subsection{Mineral dust freezing experiments from the Zurich Ice Nucleation Chamber (ZINC)}

Welti et al. (2012) (hereafter W12) studied the dependence of freezing probability on residence time for droplets containing particles of mineral dust using the ZINC continuous flow diffusion chamber. The mineral dust used by W12 was supplied by the chemical company Fluka as kaolinite, but contained a range of minerals including feldspar and it has been suggested that it is this feldspar content which controls its ice nucleating ability (Atkinson et al., 2013). In their experiment W12 size-selected single particles, immersed them in 

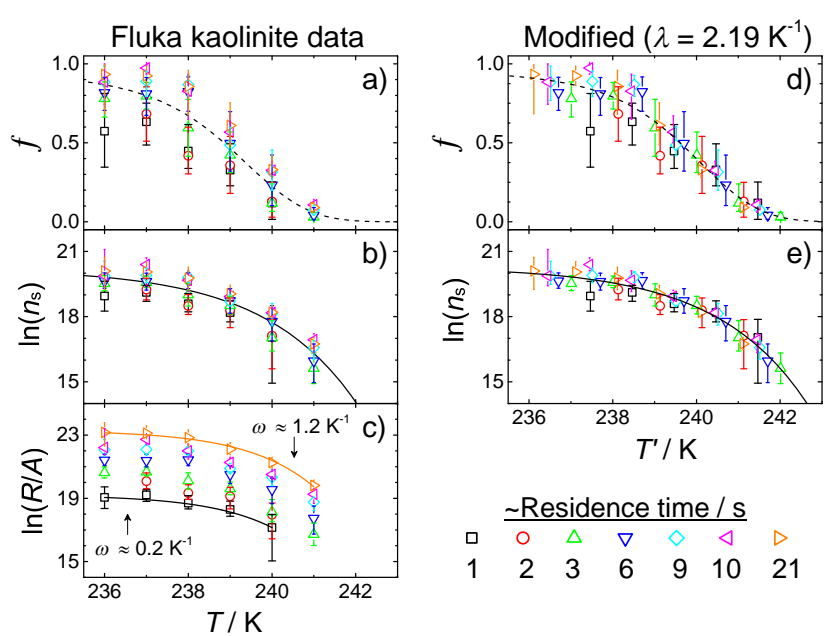

Figure 8. The freezing of droplets containing size-selected $400 \mathrm{~nm}$ kaolinite (Fluka) particles in a CFDC instrument from Welti et al. (2012). Layout as in Fig. 5. Residence times at constant temperature ranged from 1.11 to $21.4 \mathrm{~s}$ at temperatures from 236 to $241 \mathrm{~K} . R / A(T)$ values, shown in (c), do not fall onto a single line and exhibit a consistent separation with increasing residence time. Modified $n_{\mathrm{S}}\left(T^{\prime}\right)$ data were minimised in order to determine a value of $\lambda$ that best describes the time dependence, resulting in $\lambda=2.19 \mathrm{~K}^{-1}$. The minimised $n_{\mathrm{S}}\left(T^{\prime}\right)$ values and corresponding fit $(\mathrm{RMSE}=0.047)$ are shown in $(\mathbf{e})$. For comparison the same fitting function was applied to the raw $n_{\mathrm{S}}(T)$ data $(\mathrm{RMSE}=0.076)$ and is shown in (b). These two functions were used to reproduce a $1 \mathrm{~K} \mathrm{~min}^{-1}$ cooling experiment and are shown as dashed lines in (a) and (d). Error bars are reproduced from Welti et al. (2012).

supercooled droplets, and passed the droplets into the ZINC instrument. Within ZINC the droplets experienced isothermal conditions and the frozen fraction was determined using a depolarisation detector. Variable flow rates and a series of detection points provide a range of residence times, and by performing experiments at several temperature W12 built up $f(T)$ curves for a range of residence times. For this study we use the data for $400 \mathrm{~nm}$ particles. The data are shown in Fig. 8a along with derived $n_{\mathrm{s}}(T)$ and $R / A(T)$ values in $\mathrm{b}$ and c, respectively. Similar to the K-feldspar data the $R / A(T)$ values for the mineral dust do not fall onto a single line and show a separation between residence times consistent with a multiple-component system. Therefore, in order to determine the value of $\lambda$ that describes the residence-time dependence, the same procedure was followed as in Sect. 4.2 for K-feldspar.

Each data point represents a single isothermal experiment with a single residence time, $t$. Hence, Eq. (21) can be used to modify each data point with $T^{\prime}=T_{\text {experiment }}-\beta(t)$, assuming that the species can be characterised by a single value for $\lambda$. Using derived $n_{\mathrm{s}}(T)$ values, with INP surface area per droplet calculated assuming a spherical particle $400 \mathrm{~nm}$ in diameter as per the experiment, $\lambda$ was systematically varied until the $n_{\mathrm{S}}\left(T^{\prime}\right)$ values converged onto a single line, again described by an exponential fit to $\ln \left(n_{\mathrm{S}}\right)$. This resulted in $\lambda=2.19 \mathrm{~K}^{-1}$ with a $\ln \left(n_{\mathrm{s}}\right)$ RMSE of 0.047 , and is shown in Fig. 8e. For comparison, an exponential fit describing the raw $n_{\mathrm{s}}(T)$ data resulted in a RMSE of 0.076 . The two exponential fits were used to reproduce the expected fraction frozen data for a $1 \mathrm{~K} \mathrm{~min}^{-1}$ cooling experiment, and are plotted along with the observed and normalised fraction frozen data set in Fig. 8a and d, respectively. The range of $\omega$ determined from the $\ln (R / A)$ fits in Fig. 8c was estimated as $1.2 \mathrm{~K}^{-1}$ at $240.5 \mathrm{~K}$ and $0.2 \mathrm{~K}^{-1}$ at $237.5 \mathrm{~K}$. These values are lower than the minimised value of $\lambda\left(2.19 \mathrm{~K}^{-1}\right)$ suggesting that the mineral dust sample used in the W12 study is a diverse species and requires a multiple-component model to describe its freezing behaviour, which agrees with the conclusions of W12.

Similar to the kaolinite and K-feldspar examples the determined value of $\lambda$ was used to reproduce the expected decay of liquid droplets over time. With CFDC (Continuous Flow Diffusion Chamber) instruments the cooling from ambient temperature to the experimental temperature is very rapid and therefore the distribution of INP efficiency per droplet can be assumed to be represented by the function of $n_{\mathrm{s}}\left(T^{\prime}\right)$ determined in Fig. 8e. To calculate the expected decay of liquid droplets with time Eq. (26) was used with the value of $\lambda\left(2.19 \mathrm{~K}^{-1}\right)$ determined previously. The experimental data, along with the expected decay, are shown in Fig. 9. It can be seen that at high temperatures $(241-239 \mathrm{~K})$ the FROST framework is able to reproduce the experimental decay very well. However, at lower temperatures (238-236 K) there are large differences, especially for longer residence times. The reported errors bars are large for the lowest temperature data and suggest an increasing uncertainty with decreasing temperature. Also the fraction of droplets frozen is expected to increase with decreasing temperature as stated by W12. This suggests a potential experimental issue, which would explain the discrepancies.

Here the FROST framework has been used to both normalise isothermal experiments performed over a range of residence times, and determine a value of $\lambda$ that can be used to potentially describe the cooling-rate and time-dependent behaviour of this mineral dust in simulations. This example additionally highlights the necessity to use relatively pure samples in order to limit uncertainties due to multiple INP species.

\subsection{Volcanic ash from ZINC and AIDA}

In this final example the framework is used to normalise droplet freezing data from two fundamentally different experimental methods. Following the eruption of Eyjafjallajökull in Iceland during April 2010, a single sample of volcanic ash was collected and analysed to investigate its freezing characteristics in the AIDA (Aerosol Interactions and Dynamics in the Atmosphere) expansion chamber (Steinke et al., 2011; hereafter S11) and the ZINC ice nucleating 


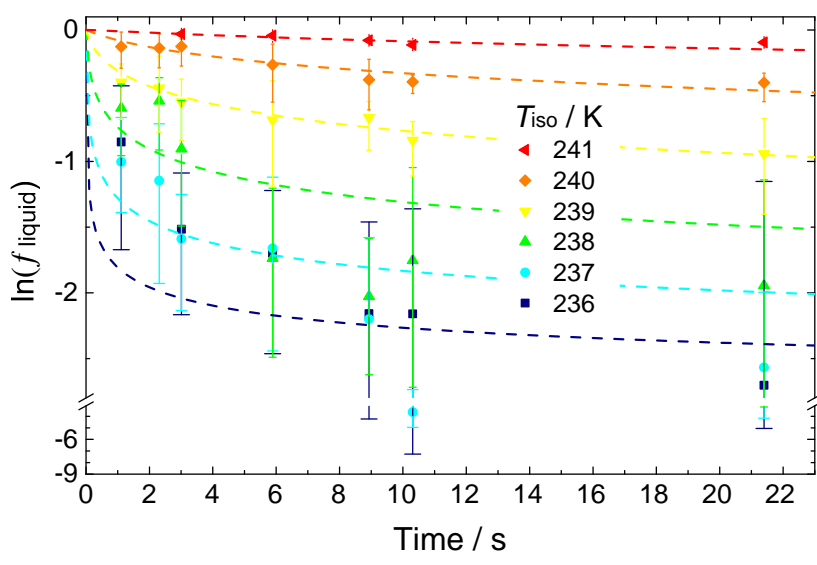

Figure 9. Experimental fraction unfrozen data for droplets containing Fluka kaolinite (symbols) in Fig. 8a (Welti et al., 2012) plotted as a function of time and temperature. We also plot the expected decay of liquid droplets with time determined using Eq. (26) with the function of $n_{\mathrm{S}}\left(T^{\prime}\right)$ in Fig. 8e and $\lambda=2.19 \mathrm{~K}^{-1}$. The expected decay at each temperature is shown as a dashed line.

chamber (Hoyle et al., 2011; hereafter H11). The ZINC instrument, as described in the previous section, was used to determine the total fraction of droplets frozen over a range of temperatures $(230 \leq T \leq 247 \mathrm{~K})$ with a residence time of $12 \mathrm{~s}$ at each temperature; each supercooled droplet contained a single immersed particle, which ranged from $\sim 0.1$ to $3 \mu \mathrm{m}$ in diameter, $D$. The $84 \mathrm{~m}^{3}$ AIDA cloud chamber is capable of simulating an ascending, cooling air parcel, and is coupled to an array of instruments, which were used to determine the freezing characteristics of the same volcanic ash sample; in this method the dust sample $(\sim 0.1 \leq D \leq \sim 15 \mu \mathrm{m})$ is dispersed into the cloud chamber prior to expansion.

The ice nucleating efficiencies of the two data sets were compared in Murray et al. (2012) and the subsequent $f(T)$ and $n_{\mathrm{s}}(T)$ values are reproduced in Fig. 10a and b, respectively. Although the fraction frozen data appear to be consistent between studies, once plotted as $n_{\mathrm{s}}(T)$ it is clear that the two data sets, albeit with similar gradients, do not show good agreement even though the same sample was used. Figure $10 \mathrm{c}$ shows the surface-area normalised freezing rates, $R / A(T)$, calculated using the temporal conditions of each experiment. For the H11 data the experimental residence time of $12 \mathrm{~s}$ was used, and for the $\mathrm{S} 11$ a cooling rate of $1.074 \mathrm{~K} \mathrm{~min}^{-1}$ was used (determined from the point at which water saturation was reached, until the elapsed time of the experiment had reached $300 \mathrm{~s}$ as per Fig. 2 in S11). Due to the non-cumulative nature of the S11 $f(T)$ data set a polynomial fit to the data was used to determine the differential fraction frozen required to calculate $R / A(T)$ values. The two data sets fall onto a single line with a $\ln (R / A)$ RMSE of 0.22 and a gradient $\omega=-\mathrm{d} \ln (R / A) / \mathrm{d} T=0.55 \mathrm{~K}^{-1}$. Following the previous two examples, $\lambda$ was systematically varied until the $n_{\mathrm{s}}\left(T^{\prime}\right)$ values converged onto a single line described by
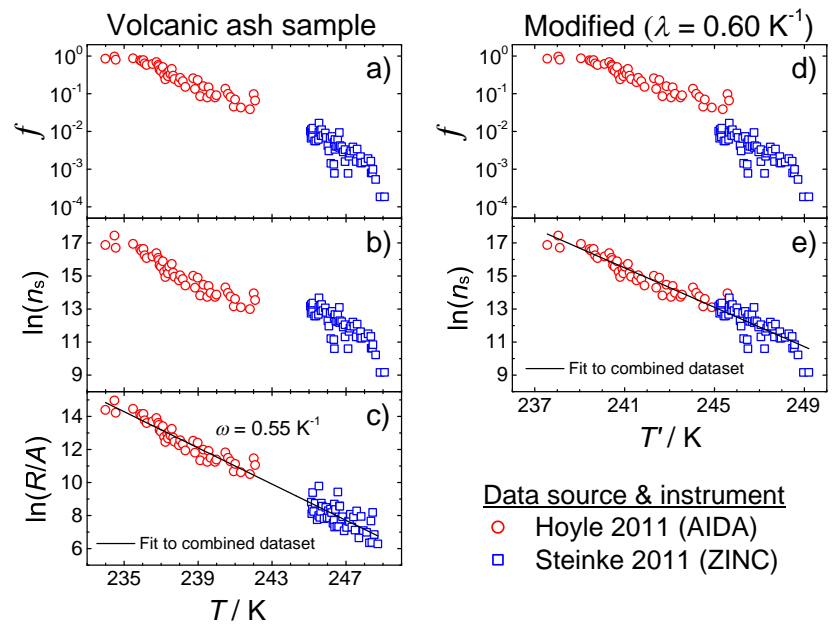

Data source \& instrument - Hoyle 2011 (AIDA) Steinke 2011 (ZINC)

Figure 10. Freezing of droplets containing volcanic ash sampled from the Eyjafjallajökull eruption in 2010. Layout as in Fig. 5. Red circles represent data presented in Hoyle et al. (2011) using the ZINC instrument, and blue squares represent data from Steinke et al. (2011) using the AIDA expansion chamber. $n_{\mathrm{S}}(T)$ data in (b) were reproduced from Murray et al. (2012); $f(T)$ values in (a) were also determined from this data set. A fit to determined $R / A$ values in (c) resulted in $\omega=0.55 \mathrm{~K}^{-1}$. The raw $n_{\mathrm{S}}(T)$ data were modified by iteratively decreasing $\lambda$ until $n_{\mathrm{S}}\left(T^{\prime}\right)$ values collapsed on a single line, resulting in $\lambda=0.60 \mathrm{~K}^{-1}$. The similarity in $\omega$ and $\lambda$ suggests that this volcanic ash sample behaves as a single-component system.

an exponential fit to $\ln \left(n_{\mathrm{s}}\right)$, resulting in $\lambda=0.60 \mathrm{~K}^{-1}$. Applying this value to Eqs. (20) and (21) results in $\beta(r)=-0.12 \mathrm{~K}$ and $\beta(t)=-3.57 \mathrm{~K}$ for the $\mathrm{S} 11$ and $\mathrm{H} 11$ data sets, respectively. Figure $10 \mathrm{~d}$ and e show the subsequently modified $f\left(T^{\prime}\right)$ and $n_{\mathrm{s}}\left(T^{\prime}\right)$ data, respectively. The modified fraction frozen data show a difference between data sets due to the larger surface-area per droplet in the H11 experiments (also evident in Fig. 10b). The $n_{\mathrm{s}}\left(T^{\prime}\right)$ data are shown in Fig. 10e, with a linear fit to the combined data set producing a $\ln \left(n_{\mathrm{S}}\right)$ RMSE of 0.25 .

In this example $\omega\left(0.55 \mathrm{~K}^{-1}\right)$ and $\lambda\left(0.60 \mathrm{~K}^{-1}\right)$ are similar, which suggests that this INP species is reasonably described by a single-component system (where $\omega=\lambda$ ). On application of $\lambda=\omega=0.55 \mathrm{~K}^{-1}$ a fit to the modified data produces a RMSE of 0.26 , which is very similar to the minimised RMSE value (0.25) used to determine $\lambda$, which supports this conclusion. However, Murray et al. (2012), from which these data were reproduced, state that the average surface area per droplet determined for the H11 data set may be over-predicted, which could potentially impact these results. The $n_{\mathrm{S}}$ and $R / A$ values would shift to higher values and subsequently $\omega$ would increase slightly and $\lambda$ would also increase but by a larger factor. In this scenario $\omega<\lambda$, which would suggest that the volcanic ash sample is a multiplecomponent system. 
Fornea et al. (2009) also performed an immersion mode experiment using a volcanic ash sample from Mount St Helens. In their experiments single particles with a diameter of $250 \leq D \leq 300 \mu \mathrm{m}$ were immersed within five $2 \mu \mathrm{L}$ droplets and each subjected to 25 freeze-thaw events on a cold-stage instrument. Additionally, as a means of testing the sensitivity to cooling rate, droplets containing the same volcanic ash sample were subjected to freeze-thaw cycles, but cooled at different rates $\left(1-10 \mathrm{~K} \mathrm{~min}^{-1}\right)$. The freeze-thaw experiments resulted in an average $\sigma_{T_{\text {freeze }}}$ of $2.0 \mathrm{~K}$ and the variable cooling experiments resulted in a shift in the average freezing temperature by $3.6 \mathrm{~K}$ (upon a change from 1 to $10 \mathrm{~K} \mathrm{~min}^{-1}$ ) without any change in $\sigma_{T_{\text {freeze }}}$. Applying these data to the FROST framework Eqs. (10) and (20) were used to determine $\lambda$, resulting in $\lambda=0.635 \mathrm{~K}^{-1}$ and $\lambda=0.640 \mathrm{~K}^{-1}$ for the freeze-thaw and cooling experiments, respectively. The first important point worth noting is that these two values, determined from distinct experimental and analysis methods, show very good agreement. Secondly, a comparison to the values determined for the Eyjafjallajökull ash sample ( $\omega=0.55 \mathrm{~K}^{-1}$ and $\lambda=0.60 \mathrm{~K}^{-1}$ ) shows that there is a strong similarity with regards to the magnitude of $\lambda$. Even though these volcanic ash samples are from different sources these results suggest that they have similar time-dependent properties. These additional results provide evidence that the $\lambda$ value determined for the Eyjafjallajökull sample is robust, and therefore supports the conclusion that the Eyjafjallajökull ash sample tested is a single-component species.

\section{Discussion}

\subsection{The sensitivity of freezing probability to the time dependence of nucleation}

It is apparent that the stochastic behaviour of ice nucleation can be manifested as both a residence-time and cooling-rate dependence. For INP species characterised by a single value of $\lambda$ this collective time dependence can be reconciled and predicted using the FROST framework. Within this framework a change in cooling rate or residence time can be seen as an equivalent shift in temperature along the function describing the nucleation rate. This function is typically exponential and therefore can have a significant effect on the resulting freezing probability.

A first-order indication of the potential importance of time dependence is shown in Fig. 11 where values of $\beta_{\text {cool }}$ and $\beta_{\text {iso }}$ for $0.4 \geq \lambda \geq 10 \mathrm{~K}^{-1}$ have been plotted. Each point represents the shift of a specific fraction frozen, by a temperature $\beta \mathrm{K}$, that results from a fractional change in either cooling rate or residence time for a species with a specific value of $\lambda$ as per Eqs. (8) and (9). This plot shows how materials with a small value of $\lambda$ (corresponding to a shallow gradient $\omega$ in a single-component system) are more sensitive to timescale;

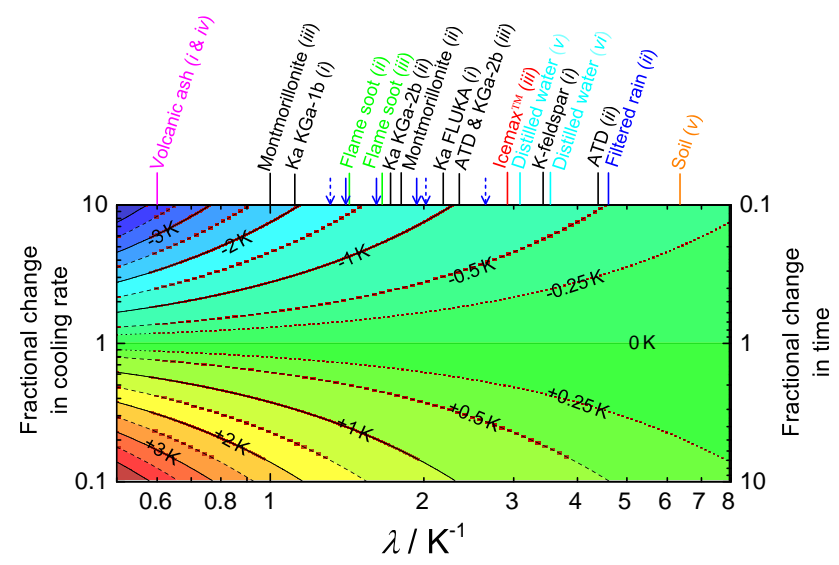

Figure 11. The shift in temperature $\beta \mathrm{K}$ that will result from a fractional change in cooling rate or residence time as a function of $\lambda$. Estimated values include those determined from (i) this study, (ii) Wright et al. (2013) cooling experiments, (iii) Wright et al. (2013) freeze-thaw experiments, (iv) Fornea et al. (2009), (v) Vali (2008), and (vi) Vali and Stansbury (1966). INP samples are colour coded depending on INP type. Blue (solid and dashed) arrows correspond to rain samples (unfiltered and filtered) from the freeze-thaw experiments presented in Wright et al. (2013).

with a decreasing $\lambda$ corresponding to an increasing shift by $\beta$ for the same change in timescale.

The values of $\lambda$ from this study and other experimental data sets in the literature (Vali and Stansbury, 1966; Vali, 2008; Fornea et al., 2009; Wright et al., 2013) have been included in Fig. 11; the values and associated study are additionally shown in Table 2. In each case the FROST framework was used to estimate $\lambda$ from cooling, isothermal and freeze-thaw experiments as per Eqs. (20), (21), and (10). It is clear that atmospherically relevant INPs exhibit a wide range of time-dependent behaviour. INP species that have a value of $\lambda$ with a large magnitude $\left(\lambda>4 \mathrm{~K}^{-1}\right)$, such as Icemax ${ }^{\mathrm{TM}}$, and Arizona Test Dust (ATD), will exhibit very little time dependence and would likely be well approximated by a singular freezing model. For those with a small magnitude (especially $\lambda<1 \mathrm{~K}^{-1}$ ) such as kaolinite KGa-1b and volcanic ash, the significant cooling-rate and residence-time dependence must be taken into account. It is interesting to note that in many previous studies into the role of time dependence (Vali and Stansbury, 1966; Vali, 2008; Welti et al., 2012), which formed the basis of the argument that time dependence is of secondary importance, the materials used have larger $\lambda$ values and are therefore less sensitive to temporal conditions.

It is also apparent in Fig. 11 that more efficient INPs tend to exhibit a larger value of $\lambda$. This behaviour was also noted by Vali (2014). For example, bacterial INP and soils which contain some of the most efficient INP we know of also have the largest values of $\lambda$. Interestingly, CNT predicts that $\lambda$ is larger at higher temperatures. However, there are also exceptions to this "rule". Values of $\lambda$ determined from freeze-thaw 
Table 2. Summary of $\lambda$ values from various immersion mode studies determined using the FROST framework.

\begin{tabular}{|c|c|c|}
\hline Study and experimental method & Material & $\lambda / \mathrm{K}^{-1}$ \\
\hline Vali and Stansbury (1966) - cooling & Distilled water & 3.5 \\
\hline \multirow[t]{2}{*}{ Vali (2008) - freeze-thaw } & Soil & 6.3 \\
\hline & Distilled water & 3.0 \\
\hline Fornea et al. (2009) - freeze-thaw & Volcanic ash (Mt St Helens) & 0.6 \\
\hline Fornea et al. (2009) - cooling & Volcanic ash (Mt St Helens) & 0.6 \\
\hline $\begin{array}{l}\text { Hoyle et al. (2011) - isothermal } \\
\& \text { Steinke et al. (2011) - cooling }\end{array}$ & Volcanic ash (Eyjafjallajökull) & 0.6 \\
\hline Welti et al. (2012) - isothermal & Kaolinite Fluka & 2.2 \\
\hline \multirow[t]{12}{*}{ Wright et al. (2013) - freeze-thaw } & Icemax $^{\mathrm{TM}}$ & 2.9 \\
\hline & ATD & 2.3 \\
\hline & Montmorillonite & 0.9 \\
\hline & Kaolinite KGa-2b & 2.2 \\
\hline & Flame soot & 1.7 \\
\hline & Filtered rain \#1 & 1.3 \\
\hline & Filtered rain \#2 & 2.0 \\
\hline & Filtered rain \#3 & 2.6 \\
\hline & Filtered rain \#4 & 1.9 \\
\hline & Unfiltered rain \#1 & 1.6 \\
\hline & Unfiltered rain \#2 & 1.4 \\
\hline & Unfiltered rain \#3 & 1.9 \\
\hline \multirow[t]{8}{*}{ Wright et al. (2013) - cooling } & Icemax $^{\mathrm{TM}}$ & N/A* \\
\hline & ATD & 4.4 \\
\hline & Montmorillonite & 1.8 \\
\hline & Kaolinite KGa-2b & 1.7 \\
\hline & Flame soot & 1.4 \\
\hline & Filtered rain \#3 & 4.6 \\
\hline & Filtered rain \#4 & 4.6 \\
\hline & Unfiltered rain \#1 & N/A* \\
\hline \multirow[t]{2}{*}{ This study - cooling and isothermal } & Kaolinite KGa-1b & 1.1 \\
\hline & K-feldspar & 3.4 \\
\hline
\end{tabular}

* Due to the experimental scatter in reported data it was not possible to estimate $\lambda$ for these species.

experiments by Wright et al. (2013) for kaolinite KGa-2b and Icemax $^{\mathrm{TM}}$ are very similar, but the Icemax ${ }^{\mathrm{TM}}$ sample nucleated ice at much warmer temperatures. More work needs to be done on what factors control the value of $\lambda$.

The finding that ice nucleation by different materials has different sensitivities to time is important because it changes the way we should frame the debate of whether time dependence plays an important role in ice nucleation. In the past the question has been whether time dependence is important, but this question should be rephrased to whether a particular INP species has a strong time dependence or not, and at what point this stops having an impact on ice nucleation rates; i.e. is there a limiting value of $\lambda$ beyond which the singular freezing model is adequate?

\subsection{Representing complex INP populations in cloud models}

The range in time-dependent behaviour shown for the INP species in Fig. 11 leads to the question of how to best imple- ment this behaviour for a complex multiple-component INP sample, or population, where each component has a characteristic time dependence, within a cloud model.

The time dependence of a population of INPs containing many separate species may be dominated by a single component, and therefore a single value or temperature-dependent function of $\lambda$. Where distinct components are dominant in different temperature ranges it would be possible to have a temperature-dependent function of $\lambda$ to reflect the relative dominance of each component. For multiple-species aerosol where no single component is observably dominant, the population of particles/droplets would need to be split into separate components and treated as an externally mixed population.

Several immersion mode freezing schemes have been developed that incorporate multiple components in order to improve the treatment of INP populations in models: Diehl and Wurzler (2010) used a simple fractional occurrence factor to model potential immersion mode droplets containing bacterial, mineral and soot INPs; Phillips et al. (2008) 
used classifications of dust/metallic, black carbon and organic aerosols in a similar method for modelling a population of INP species; and Barahona (2012) introduced the ice nucleation spectrum framework, capable of relating different aerosol properties to ice nucleation in the deposition mode, with the potential to extend to immersion freezing.

Whilst these models are capable of describing separate species it may be more realistic to represent a series of dominant components so that the time dependence and interparticle variability can be accurately described for a complex, evolving INP population. To achieve this, the $\lambda$ characterisation of each component needs to be determined through a series of isothermal and cooling experiments on INP samples that have very high purities. Commonly tested samples, such as ATD and illite, are comprised of several mineralogical components and may therefore contain multiple INP species. Once $\lambda$ has been determined for the individual or dominant component of the species, the normalised data can be used with the FROST framework.

\section{Conclusions}

The range of instruments and techniques that are used for characterising the freezing properties of INP species result in different temporal conditions; i.e. CFDC instruments routinely use a constant temperature and residence time, whereas cold-stage instruments and cloud chambers typically cool droplets at some rate to determine freezing behaviour. Taking into account the differences in timescale between these experiments and translating this information to cloud formation in the atmosphere has been a challenge.
In this study we have developed a new framework to address this challenge. This framework is underpinned by the finding that the temperature shift observed upon a change in cooling rate is directly related to the slope $-\mathrm{d} \ln \left(J_{\mathrm{s}, i}\right) / \mathrm{d} T(\lambda)$. We also extended this relationship to freezing experiments conducted under isothermal conditions with varying residence times, and the variability in freezing temperature observed in freeze-thaw experiments. We refer to this framework as the Framework for Reconciling Observable Stochastic Time-dependence (FROST) and use it in combination with the singular freezing model. Therefore the FROST framework can be used to describe both the interparticle variability and the stochastic nature of ice nucleation within a simple parameterisation.

To test the FROST framework, data obtained from a variety of instruments (including the ZINC, AIDA expansion chamber and two cold-stage instruments) were analysed to determine the value for $\lambda$ that best described the observed time dependence of each species. It is striking that the parameter $\lambda$ depends strongly on the material, with more efficient INPs tending to have the largest $\lambda$, and therefore weakest time dependence, whereas less efficient INPs such as kaolinite $(\mathrm{KGa}-1 \mathrm{~b})$ have the smallest $\lambda$, and therefore strongest time dependence. More work is needed in order to quantify $\lambda$ for other atmospherically relevant INPs. 
Appendix A: Glossary of terms

\begin{tabular}{|c|c|}
\hline Notation & Description \\
\hline$J_{\mathrm{s}, i}(T)$ & The nucleation-rate coefficient $\left(\mathrm{cm}^{-2} \mathrm{~s}^{-1}\right)$ for a single component $i$. \\
\hline$\lambda$ & $\begin{array}{l}\text { The temperature dependence }\left(\mathrm{K}^{-1}\right) \text { of the nucleation-rate coefficient of a single com- } \\
\text { ponent }-\operatorname{dln}\left(J_{\mathrm{s}, i}\right) / \mathrm{d} T \text {. }\end{array}$ \\
\hline$R / A(T)$ & $\begin{array}{l}\text { The freezing rate, } R \text {, normalised to surface-area }\left(\mathrm{cm}^{-2} \mathrm{~s}^{-1}\right) \text { derived from experimental } \\
\text { data using Eq. (1) and initially assuming a uniform INP species so that } R / A=J_{\mathrm{s}, i} \text {. }\end{array}$ \\
\hline$\omega$ & $\begin{array}{l}\text { The temperature dependence }\left(\mathrm{K}^{-1}\right) \text { of the normalised freezing rate }-\mathrm{d} \ln (R / A) / \mathrm{d} T \text {. If } \\
\omega=\lambda \text { then the species being tested is uniform and } R / A=J_{\mathrm{s}, i} \text {, whereas if } \omega \neq \lambda \text { then } \\
\text { the species being tested is not uniform and } R / A \neq J_{\mathrm{s}, i} .\end{array}$ \\
\hline$\beta$ & Systematic shift in temperature (K) of the fraction frozen $f(T)$ upon a temporal change. \\
\hline$\beta(r)$ & $\begin{array}{l}\text { Systematic shift in temperature }(\mathrm{K}) \text { of the fraction frozen } f(T) \text { as a function of cooling } \\
\text { rate }(r) \text { in kelvin per minute }\left(\mathrm{K} \mathrm{min}^{-1}\right) \text { upon normalising to a cooling rate of } 1 \mathrm{~K} \mathrm{~min}^{-1} \text {. }\end{array}$ \\
\hline$\beta(t)$ & $\begin{array}{l}\text { Systematic shift in temperature (K) of the fraction frozen } f(T) \text { as a function of resi- } \\
\text { dence time }(t) \text { in seconds upon normalising to a cooling rate of } 1 \mathrm{~K} \mathrm{~min}^{-1} \text {. }\end{array}$ \\
\hline$T^{\prime}$ & $\begin{array}{l}\text { The modified temperature of an experimentally determined data point normalised to a } \\
\text { cooling experiment at } 1 \mathrm{~K} \mathrm{~min}^{-1} \text { where } T^{\prime}=T_{\text {experiment }}-\beta \text {. }\end{array}$ \\
\hline$n_{\mathrm{S}}(T)$ & Ice active site density, $\left(\mathrm{cm}^{-2}\right)$ derived from experimental data using Eq. (23). \\
\hline$n_{\mathrm{S}}\left(T^{\prime}\right)$ & $\begin{array}{l}n_{\mathrm{S}}(T) \text { modified by a temperature } \beta \mathrm{K} \text { as above, thus normalising all data points to a } \\
\text { cooling rate of } 1 \mathrm{~K} \mathrm{~min}^{-1} \text {. }\end{array}$ \\
\hline$f\left(T^{\prime}\right)$ & $\begin{array}{l}\text { The cumulative fraction frozen, } f(T) \text { modified by a temperature } \beta \mathrm{K} \text {, thus normalising } \\
\text { all data points to a cooling rate of } 1 \mathrm{~K} \mathrm{~min}^{-1} \text {. }\end{array}$ \\
\hline
\end{tabular}




\section{The Supplement related to this article is available online at doi:10.5194/acp-14-8501-2014-supplement.}

Acknowledgements. We thank A. Welti for kindly providing the kaolinite (K-SA) data set and D. O'Sullivan for helpful discussions. Two anonymous reviewers are also thanked for their valuable comments and suggestions. We thank G. Vali for working with us in a collaborative effort to generate a consistent set of nomenclature between this paper and his recent paper in this journal. We gratefully acknowledge the European Research Council (FP7, 240449 ICE) and the Natural Environment Research Council (NE/I019057/1; NE/K004417/1; NE/I020059/1; NE/I013466/1; NE/H001050/1; NE/D009308/1) for funding.

Edited by: M. Petters

\section{References}

Ansmann, A., Mattis, I., Müller, D., Wandinger, U., Radlach, M., Althausen, D., and Damoah, R.: Ice formation in Saharan dust over central Europe observed with temperature/humidity/aerosol Raman lidar, J. Geophys. Res.-Atmos., 110, D18S12, doi:10.1029/2004jd005000, 2005.

Ansmann, A., Tesche, M., Seifert, P., Althausen, D., Engelmann, R., Fruntke, J., Wandinger, U., Mattis, I., and Muller, D.: Evolution of the ice phase in tropical altocumulus: SAMUM lidar observations over Cape Verde, J. Geophys. Res.-Atmos., 114, D17208, doi:10.1029/2008jd011659, 2009.

Atkinson, J. D., Murray, B. J., Woodhouse, M. T., Whale, T. F., Baustian, K. J., Carslaw, K. S., Dobbie, S., O’Sullivan, D., and Malkin, T. L.: The importance of feldspar for ice nucleation by mineral dust in mixed-phase clouds, Nature, 498, 355-358, doi:10.1038/nature12278, 2013.

Barahona, D.: On the ice nucleation spectrum, Atmos. Chem. Phys., 12, 3733-3752, doi:10.5194/acp-12-3733-2012, 2012.

Broadley, S. L., Murray, B. J., Herbert, R. J., Atkinson, J. D., Dobbie, S., Malkin, T. L., Condliffe, E., and Neve, L.: Immersion mode heterogeneous ice nucleation by an illite rich powder representative of atmospheric mineral dust, Atmos. Chem. Phys., 12, 287-307, doi:10.5194/acp-12-287-2012, 2012.

Conen, F., Morris, C. E., Leifeld, J., Yakutin, M. V., and Alewell, C.: Biological residues define the ice nucleation properties of soil dust, Atmos. Chem. Phys., 11, 9643-9648, doi:10.5194/acp-119643-2011, 2011.

Connolly, P. J., Möhler, O., Field, P. R., Saathoff, H., Burgess, R., Choularton, T., and Gallagher, M.: Studies of heterogeneous freezing by three different desert dust samples, Atmos. Chem. Phys., 9, 2805-2824, doi:10.5194/acp-9-2805-2009, 2009.

Cui, Z. Q., Carslaw, K. S., Yin, Y., and Davies, S.: A numerical study of aerosol effects on the dynamics and microphysics of a deep convective cloud in a continental environment, J. Geophys. Res.-Atmos., 111, D05201, doi:10.1029/2005jd005981, 2006.

Cziczo, D. J., Stetzer, O., Worringen, A., Ebert, M., Weinbruch, S., Kamphus, M., Gallavardin, S. J., Curtius, J., Borrmann, S., Froyd, K. D., Mertes, S., Mohler, O., and Lohmann, U.: In- advertent climate modification due to anthropogenic lead, Nat. Geosci., 2, 333-336, doi:10.1038/Ngeo499, 2009.

de Boer, G., Morrison, H., Shupe, M. D., and Hildner, R.: Evidence of liquid dependent ice nucleation in high-latitude stratiform clouds from surface remote sensors, Geophys. Res. Lett., 38, L01803, doi:10.1029/2010g1046016, 2011.

Demott, P. J.: Quantitative Descriptions of Ice Formation Mechanisms of Silver Iodide-Type Aerosols, Atmos. Res., 38, 63-99, doi:10.1016/0169-8095(94)00088-U, 1995.

Diehl, K. and Wurzler, S.: Air parcel model simulations of a convective cloud: Bacteria acting as immersion ice nuclei, Atmos. Environ., 44, 4622-4628, doi:10.1016/j.atmosenv.2010.08.003, 2010.

Dobbie, S. and Jonas, P.: Radiative influences on the structure and lifetime of cirrus clouds, Q. J. Roy. Meteor. Soc., 127, 26632682, doi:10.1256/Smsqj.57807, 2001.

Durant, A. J. and Shaw, R. A.: Evaporation freezing by contact nucleation inside-out, Geophys. Res. Lett., 32, L20814, doi:10.1029/2005g1024175, 2005.

Ervens, B. and Feingold, G.: Sensitivities of immersion freezing: Reconciling classical nucleation theory and deterministic expressions, Geophys. Res. Lett., 40, 3320-3324, doi:10.1002/Grl.50580, 2013.

Field, P. R., Heymsfield, A. J., Shipway, B. J., DeMott, P. J., Pratt, K. A., Rogers, D. C., Stith, J., and Prather, K. A.: Ice in Clouds Experiment-Layer Clouds. Part II: Testing Characteristics of Heterogeneous Ice Formation in Lee Wave Clouds, J. Atmos. Sci., 69, 1066-1079, doi:10.1175/jas-d-11-026.1, 2012.

Fornea, A. P., Brooks, S. D., Dooley, J. B., and Saha, A.: Heterogeneous freezing of ice on atmospheric aerosols containing ash, soot, and soil, J. Geophys. Res.-Atmos., 114, D13201, doi:10.1029/2009jd011958, 2009.

Hartmann, D. L., Ockert-Bell, M. E., and Michelsen, M. L.: The Effect of Cloud Type on Earth's Energy Balance: Global Analysis, J. Climate, 5, 1281-1304, doi:10.1175/15200442(1992)005<1281:teocto>2.0.co;2, 1992.

Heneghan, A. F., Wilson, P. W., Wang, G. M., and Haymet, A. D. J.: Liquid-to-crystal nucleation: Automated lag-time apparatus to study supercooled liquids, J. Chem. Phys., 115, 7599-7608, doi:10.1063/1.1407290, 2001.

Hoose, C. and Möhler, O.: Heterogeneous ice nucleation on atmospheric aerosols: a review of results from laboratory experiments, Atmos. Chem. Phys., 12, 9817-9854, doi:10.5194/acp-12-98172012, 2012.

Hoyle, C. R., Pinti, V., Welti, A., Zobrist, B., Marcolli, C., Luo, B., Höskuldsson, Á., Mattsson, H. B., Stetzer, O., Thorsteinsson, T., Larsen, G., and Peter, T.: Ice nucleation properties of volcanic ash from Eyjafjallajökull, Atmos. Chem. Phys., 11, 9911-9926, doi:10.5194/acp-11-9911-2011, 2011.

Kashchiev, D., Borissova, A., Hammond, R. B., and Roberts, K. J.: Effect of cooling rate on the critical undercooling for crystallization, J. Cryst. Growth, 312, 698-704, doi:10.1016/j.jcrysgro.2009.12.031, 2009.

Kulkarni, G. and Dobbie, S.: Ice nucleation properties of mineral dust particles: determination of onset RHi, IN active fraction, nucleation time-lag, and the effect of active sites on contact angles, Atmos. Chem. Phys., 10, 95-105, doi:10.5194/acp-10-95-2010, 2010.

Ladino, L., Stetzer, O., Lüönd, F., Welti, A., and Lohmann, U.: Contact freezing experiments of kaolinite particles with 
cloud droplets, J. Geophys. Res.-Atmos., 116, D22202, doi:10.1029/2011jd015727, 2011.

Ladino Moreno, L. A., Stetzer, O., and Lohmann, U.: Contact freezing: a review of experimental studies, Atmos. Chem. Phys., 13, 9745-9769, doi:10.5194/acp-13-9745-2013, 2013.

Lau, K. M. and Wu, H. T.: Warm rain processes over tropical oceans and climate implications, Geophys. Res. Lett., 30, 2290, doi:10.1029/2003g1018567, 2003.

Levine, J.: Statistical explanation of spontaneous freezing of water droplets, NACA Tech. Note, 2234, 1950.

Lüönd, F., Stetzer, O., Welti, A., and Lohmann, U.: Experimental study on the ice nucleation ability of size-selected kaolinite particles in the immersion mode, J. Geophys. Res., 115, D14201, doi:10.1029/2009jd012959, 2010.

Marcolli, C., Gedamke, S., Peter, T., and Zobrist, B.: Efficiency of immersion mode ice nucleation on surrogates of mineral dust, Atmos. Chem. Phys., 7, 5081-5091, doi:10.5194/acp-7-50812007, 2007.

Mortazavi, R., Hayes, C. T., and Ariya, P. A.: Ice nucleation activity of bacteria isolated from snow compared with organic and inorganic substrates, Environ. Chem., 5, 373-381, doi:10.1071/EN08055, 2008.

Murray, B. J., Broadley, S. L., Wilson, T. W., Bull, S. J., Wills, R. H., Christenson, H. K., and Murray, E. J.: Kinetics of the homogeneous freezing of water, Phys. Chem. Chem. Phys., 12, 1038010387, doi:10.1039/c003297b, 2010.

Murray, B. J., Broadley, S. L., Wilson, T. W., Atkinson, J. D., and Wills, R. H.: Heterogeneous freezing of water droplets containing kaolinite particles, Atmos. Chem. Phys., 11, 4191-4207, doi:10.5194/acp-11-4191-2011, 2011.

Murray, B. J., O’Sullivan, D., Atkinson, J. D., and Webb, M. E.: Ice nucleation by particles immersed in supercooled cloud droplets, Chem. Soc. Rev., 41, 6519-6554, doi:10.1039/c2cs35200a, 2012.

Niedermeier, D., Hartmann, S., Shaw, R. A., Covert, D., Mentel, T. F., Schneider, J., Poulain, L., Reitz, P., Spindler, C., Clauss, T., Kiselev, A., Hallbauer, E., Wex, H., Mildenberger, K., and Stratmann, F.: Heterogeneous freezing of droplets with immersed mineral dust particles - measurements and parameterization, Atmos. Chem. Phys., 10, 3601-3614, doi:10.5194/acp-10-36012010, 2010.

Niedermeier, D., Shaw, R. A., Hartmann, S., Wex, H., Clauss, T., Voigtländer, J., and Stratmann, F.: Heterogeneous ice nucleation: exploring the transition from stochastic to singular freezing behavior, Atmos. Chem. Phys., 11, 8767-8775, doi:10.5194/acp11-8767-2011, 2011.

O'Sullivan, D., Murray, B. J., Malkin, T. L., Whale, T. F., Umo, N. S., Atkinson, J. D., Price, H. C., Baustian, K. J., Browse, J., and Webb, M. E.: Ice nucleation by fertile soil dusts: relative importance of mineral and biogenic components, Atmos. Chem. Phys., 14, 1853-1867, doi:10.5194/acp-14-1853-2014, 2014.

Phillips, V. T. J., Donner, L. J., and Garner, S. T.: Nucleation processes in deep convection simulated by a cloud-system-resolving model with double-moment bulk microphysics, J. Atmos. Sci., 64, 738-761, doi:10.1175/Jas3869.1, 2007.

Phillips, V. T. J., DeMott, P. J., and Andronache, C.: An Empirical Parameterization of Heterogeneous Ice Nucleation for Multiple Chemical Species of Aerosol, J. Atmos. Sci., 65, 2757-2783, doi:10.1175/2007JAS2546.1, 2008.
Pruppacher, H. R.: A New Look at Homogeneous Ice Nucleation in Supercooled Water Drops, J. Atmos. Sci., 52, 1924-1933, 10.1175/1520-0469(1995)052<1924:ANLAHI>2.0.CO;2, 1995.

Pruppacher, H. R. and Klett, J. D.: Microphysics of Clouds and Precipitation, 2 Edn., Kulwer Academic Publishers, Dordrecht, 1997.

Sassen, K. and Khvorostyanov, V. I.: Microphysical and radiative properties of mixed-phase altocumulus: A model evaluation of glaciation effects, Atmos. Res., 84, 390-398, doi:10.1016/j.atmosres.2005.08.017, 2007.

Sear, R. P.: Generalisation of Levine's prediction for the distribution of freezing temperatures of droplets: a general singular model for ice nucleation, Atmos. Chem. Phys., 13, 7215-7223, doi:10.5194/acp-13-7215-2013, 2013.

Stan, C. A., Schneider, G. F., Shevkoplyas, S. S., Hashimoto, M., Ibanescu, M., Wiley, B. J., and Whitesides, G. M.: A microfluidic apparatus for the study of ice nucleation in supercooled water drops, Lab Chip, 9, 2293-2305, doi:10.1039/b906198c, 2009.

Steinke, I., Möhler, O., Kiselev, A., Niemand, M., Saathoff, H., Schnaiter, M., Skrotzki, J., Hoose, C., and Leisner, T.: Ice nucleation properties of fine ash particles from the Eyjafjallajökull eruption in April 2010, Atmos. Chem. Phys., 11, 12945-12958, doi:10.5194/acp-11-12945-2011, 2011.

Vali, G.: Quantitative Evaluation of Experimental Results an the Heterogeneous Freezing Nucleation of Supercooled Liquids, J. Atmos. Sci., 28, 402-409, doi:10.1175/15200469(1971)028<0402:QEOERA>2.0.CO;2, 1971.

Vali, G.: Nucleation terminology, J. Aerosol Sci., 16, 575-576, doi:10.1016/0021-8502(85)90009-6, 1985.

Vali, G.: Freezing Rate Due to Heterogeneous Nucleation, J. Atmos. Sci., 51, 1843-1856, doi:10.1175/15200469(1994)051<1843:FRDTHN>2.0.CO;2, 1994.

Vali, G.: Repeatability and randomness in heterogeneous freezing nucleation, Atmos. Chem. Phys., 8, 5017-5031, doi:10.5194/acp-8-5017-2008, 2008.

Vali, G.: Interpretation of freezing nucleation experiments: singular and stochastic; sites and surfaces, Atmos. Chem. Phys., 14, 5271-5294, doi:10.5194/acp-14-5271-2014, 2014.

Vali, G. and Stansbury, E. J.: Time-Dependent characteristics of the heterogeneous nucleation of ice, Can. J. Phys., 44, 477-502, doi:10.1139/p66-044, 1966.

Welti, A., Lüönd, F., Kanji, Z. A., Stetzer, O., and Lohmann, U.: Time dependence of immersion freezing: an experimental study on size selected kaolinite particles, Atmos. Chem. Phys., 12, 9893-9907, doi:10.5194/acp-12-9893-2012, 2012.

Westbrook, C. D. and Illingworth, A. J.: The formation of ice in a long-lived supercooled layer cloud, Q. J. Roy. Meteor. Soc., 139, 2209-2221, doi:10.1002/qj.2096, 2013.

Whale, T. F., Murray, B. J., O'Sullivan, D., Umo, N. S., Baustian, K. J., Atkinson, J. D., and Morris, G. J.: A technique for quantifying heterogeneous ice nucleation in microliter supercooled water, in preparation, 2014.

Wilson, P. W. and Haymet, A. D. J.: The Spread of Nucleation Temperatures of a Sample of Supercooled Liquid Is Independent of the Average Nucleation Temperature, J. Phys. Chem. B, 116, 13472-13475, doi:10.1021/jp308177b, 2012.

Wolber, P. K., Deininger, C. A., Southworth, M. W., Vandekerckhove, J., van Montagu, M., and Warren, G. J.: Identification and 
purification of a bacterial ice-nucleation protein, P. Natl. Acad. Sci. USA, 83, 7256-7260, 1986.

Wright, T. P. and Petters, M. D.: The role of time in heterogeneous freezing nucleation, J. Geophys. Res.-Atmos., 118, 3731-3743, doi:10.1002/Jgrd.50365, 2013.

Wright, T. P., Petters, M. D., Hader, J. D., Morton, T., and Holder, A. L.: Minimal cooling rate dependence of ice nuclei activity in the immersion mode, J. Geophys. Res.-Atmos., 118, 10535-510543, doi:10.1002/jgrd.50810, 2013.
Zhang, D., Wang, Z., and Liu, D.: A global view of midlevel liquidlayer topped stratiform cloud distribution and phase partition from CALIPSO and CloudSat measurements, J. Geophys. Res.Atmos., 115, D00H13, doi:10.1029/2009jd012143, 2010. 